\title{
SPATIAL VARIATIONS OF SEISMIC WAVE ATTENUATION IN THE SOUTH BAIKAL BASIN AND ADJACENT AREAS (BAIKAL RIFT)
}

\author{
A. A. Dobrynina1, 2, P. A. Predein'2,3, V. A. Sankov1,4, Ts. A. Tubanov', 3, \\ D. P.-D. Sanzhieva ${ }^{2}$, E. A. Gorbunova ${ }^{1}$ \\ ${ }^{1}$ Institute of the Earth's Crust, Siberian Branch of RAS, Irkutsk, Russia \\ ${ }^{2}$ Geological Institute, Siberian Branch of RAS, Ulan-Ude, Russia \\ ${ }^{3}$ Buryatian Branch of Federal Research Center 'Geophysical Survey of RAS', Ulan-Ude, Russia \\ ${ }^{4}$ Irkutsk State University, Irkutsk, Russia
}

\begin{abstract}
Our detailed study of the crust and upper mantle of the South Baikal basin focused on seismic coda and seismic $S$-waves attenuation and estimated seismic quality factor $\left(Q_{S}\right.$ and $\left.Q_{C}\right)$, frequency parameter $(n)$, attenuation coefficient $(\delta)$, total attenuation $\left(Q_{\mathrm{T}}\right)$, and the ratio of two components the total attenuation: intrinsic attenuation $\left(Q_{\mathrm{i}}\right)$, and attenuation due to scattering caused by the inhomogeneities of the medium ( $Q_{\mathrm{Sc}}$ ). We calculated the sizes of inhomogeneities revealed in the block medium, which put their effect on the attenuation of seismic waves in different frequency ranges. The seismic wave attenuation field was analyzed in comparison with the geological and geophysical characteristics of the medium, and a direct relationship was established between attenuation, composition and active processes in the crust and upper mantle of the studied area. According to the estimated intrinsic attenuation $\left(Q_{\mathrm{i}}\right)$ and scattering attenuation $\left(Q_{s c}\right)$ contributions into the total attenuation, intrinsic attenuation is generally dominant in the studied area, while the $Q_{\mathrm{sc}}$ component increases in the areas of large active faults.
\end{abstract}

Key words: South Baikal rift basin; seismic quality factor; attenuation; seismic coda; S-waves; earthquake; explosion; block divisibility of the medium; components of attenuation; active fault

For citation: Dobrynina A.A., Predein P.A., Sankov V.A., Tubanov Ts.A., Sanzhieva D.P.-D., Gorbunova E.A., 2019. Spatial variations of seismic wave attenuation in the South Baikal basin and adjacent areas (Baikal rift). Geodynamics \& Tectonophysics 10 (1), 147-166. doi:10.5800/GT2019-10-1-0408. 


\title{
ПРОСТРАНСТВЕННЫЕ ВАРИАЦИИ ЗАТУХАНИЯ СЕЙСМИЧЕСКИХ ВОЛН В ЮЖНОБАЙКАЛЬСКОЙ ВПАДИНЕ И ПРИЛЕГАЮЩИХ ОБЛАСТЯХ (БАЙКАЛЬСКИЙ РИФТ)
}

\author{
А. А. Добрынина 1,2 , П. А. Предеин ${ }^{2}$, В. А. Саньков ${ }^{1,3}$, Ц. А. Тубанов², \\ Д. П.-Д. Санжиева², Е. А. Горбунова ${ }^{1}$ \\ ${ }^{1}$ Институт земной коры СО РАН, Иркутск, Россия \\ 2 Геологический институт СО РАН, Улан-Удэ, Россия \\ ${ }^{3}$ Бурятский филиал Федерального исследовательского центра \\ «Единая геофизическая служба РАН», Улан-Удэ, Россия \\ ${ }^{3}$ Иркутский государственный университет, Иркутск, Россия
}

\begin{abstract}
Аннотация: Получены детальные оценки затухания $S$-волн и коды в земной коре и верхней мантии Южнобайкальской рифтовой впадины: значения сейсмической добротности $\left(Q_{\mathrm{S}}\right.$ и $\left.Q_{\mathrm{c}}\right)$, частотного параметра $(n)$, коэффициента затухания $(\delta)$, общего затухания $\left(Q_{T}\right)$, а также проведена оценка вклада двух компонент затухания - внутреннего затухания $\left(Q_{\mathrm{i}}\right)$ и затухания вследствие рассеяния на неоднородностях среды $\left(Q_{\mathrm{sc}}\right)$ - в общее затухание. Оценены размеры неоднородностей блоковой среды, оказывающих влияние на затухание сейсмических волн в различных частотных диапазонах. Сравнительный анализ поля затухания сейсмических волн и геолого-геофизических характеристик среды показывает существование прямой связи между затуханием, составом и активными процессами в земной коре и мантии региона. Оценка вклада внутреннего затухания $\left(Q_{\mathrm{i}}\right)$ и затухания вследствие рассеяния сейсмических волн на неоднородностях среды $\left(Q_{s c}\right)$ в общее затухание для рассматриваемого региона в целом выявила доминирующую роль внутреннего затухания при увеличении вклада рассеянной компоненты затухания QSC в областях крупных активных разломов.
\end{abstract}

Ключевые слова: Южнобайкальская рифтовая впадина; добротность сейсмических волн; затухание; кода; S-волны; землетрясение; взрыв; блоковая делимость среды; компоненты затухания; активный разлом

\section{1. ВВЕДЕНИЕ}

Геодинамические процессы, протекающие в земной коре и верхней мантии, приводят к деформациям, разломообразованию и изменению флюидного режима среды, что неизбежно отражается на свойствах проходящих в среде сейсмических волн - скорости распространения, частотном составе и поглощении. Например, известно, что всего $1 \%$ флюида или расплава приводит к уменьшению скоростей $S$-волн на $10 \%$ и резкому увеличению поглощения [Hammond, Humphreys, 2000]. Поглощение энергии сейсмических волн в среде связано с несколькими факторами - геометрическим расхождением волнового фронта, внутренним затуханием (intrinsic attenuation, $Q_{\mathrm{i}}$ ), вызванным неупругими свойствами реальной среды, и затуханием на неоднородностях среды (scattering attenuation, $Q_{\mathrm{sc}}$ ), на которых происходит преломление, отражение и дифракция сейсмических волн. Именно с затуханием сейсмических волн в среде связано появление на сейсмограммах коды - длинной хвостовой части сейсмограммы, следующей после регулярных волн (объемных прямых и отраженных) [Aki, 1969].
Знание региональных параметров затухания сейсмических волн необходимо для решения задач сейсмического районирования территорий разной степени детальности. Рассматриваемый в работе район Южнобайкальской впадины и окружающие ее области входят в состав Байкальской рифтовой системы (БРС) - региона с высокой сейсмической активностью и, по данным МЧС, относятся к субъектам 1-й степени опасности по возможному воздействию природных и связанных с ними техногенных катастроф. Согласно картам общего сейсмического районирования (ОСР-2015), здесь возможны сейсмические сотрясения с интенсивностью до 7-9 баллов по шкале ШСИ-17. Высокий уровень сейсмической активности исследуемых регионов подтверждается данными о палеоземлетрясениях, макросейсмическими сведениями о сильных землетрясениях исторического прошлого и информацией более чем о 150 тыс. современных землетрясений с магнитудами до 6.8 (Среднебайкальское землетрясение 29 августа 1959 г.). Помимо этого, вблизи исследуемой территории расположены объекты горнодобывающей промышленности и опасного производства, а также проходят трассы газо- и нефтепроводов. При 
этом в используемых в настоящее время картах общего сейсмического районирования Российской Федерации ОСР-97, ОСР-97* и ОСР-2012 не учитываются региональные параметры излучения и распространения сейсмических волн на отдельных территориях [Pavlenko, 2012].

Исследованиям характеристик затухания сейсмических волн в рассматриваемом регионе посвящено несколько работ. Значения добротности литосферы были получены по измерениям преобладающих периодов трехкомпонентных широкополосных записей землетрясений о. Ольхон (оз. Байкал), при этом итоговое значение $Q$ было рассчитано путем осреднения по участку с поперечными размерами 500-1000 км [Zhadin, Dergachev, 1973]. В работе [Egorkin et al., 1981] получены значения добротности продольных $\left(Q_{\mathrm{P}}\right)$ и поперечных $\left(Q_{S}\right)$ волн для консолидированной коры Сибирской платформы. Методом центральной частоты были получены данные о пространственных вариациях параметра $Q$ для Байкальской и Баргузинской впадин [Dergachev, 1982]. По записям донных и береговых станций для района Центрального Байкала получены значения добротности для прямых поперечных волн [Bukina et al., 1983]. Ю.Ф. Копничевым на основе анализа более сотни землетрясений построена карта поглощения поперечных волн в верхней мантии Байкальской рифтовой системы, а также по кода-волнам локальных землетрясений и карьерных взрывов оценен диапазон глубин, соответствующих зонам повышенного поглощения на юго-западном фланге рифта [Kopnichev, 1991]. Для Южнобайкальской впадины по записям слабых землетрясений Южного Байкала были получены характеристики затухания сейсмических волн на расстоянии 50-200 км, при расчетах добротность среды считалась независимой от частоты [Potapov et al., 1996]. С использованием сильного виброисточника для Забайкалья получены значения затухания для продольных волн, распространяющихся вдоль и вкрест простирания разломов [Emanov et al., 1999]. Авторами также ранее проводились работы по оценке затухания по сейсмической коде и прямым $P$ - и $S$-волн для рассматриваемой территории [Dobrynina, 2011; Dobrynina et al., 2011, 2016a, 2016b, 2017].

В работе проводится детальное исследование затухания $S$-волн и коды в земной коре и верхней мантии Южнобайкальской рифтовой впадины и его связи с составом и активными процессами в земной коре и мантии региона.

\section{2. ИЗУЧАЕМЫЙ РЕГИОН}

Байкальская впадина заложена в начале кайнозоя на границе Сибирской платформы и Саяно-
Байкальской складчатой области (рис. 1). В настоящей работе мы сосредоточим наше внимание на Южнобайкальской впадине. Согласно представлениям Н.А. Логачева [Logachev, 2001], она является историческим ядром БРС, от которого рифтовые структуры разрастались билатерально - на северовосток и на юго-запад.

Морфологически во впадине выделяется субширотная Култукская депрессия, ограниченная с севера крутопадающим Обручевским разломом. Далее на север простирание структур меняется на северо-восточное, но по-прежнему основным граничным разломом является ветвь Обручевской системы разломов, которая в районе южной оконечности Приольхонского блока разветвляется на два разлома: Приморский и Морской (Ольхонский).

Расположение структуры вдоль краевого шва Сибирской платформы определяет ее высокую подвижность и, как следствие, большие амплитуды вертикальных и горизонтальных смещений. Согласно данным сейсмопрофилирования, мощность рыхлых отложений во впадине составляет около 7000 м [Hutchinson et al., 1993]. Максимальные современные деформации во впадине, оцененные по данным GPS-геодезии [Sankov et al., 2014], тяготеют к ее центральной части. Скорость деформации растяжения в пределах впадины достигает $3.1 \times 10^{-8}$ год $^{-1}$. При этом скорость относительного движения блоков Сибирской платформы и Забай-

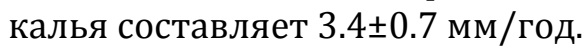

Важным обстоятельством является то, что западное плечо впадины сложено прочными архейско-протерозойскими породами Сибирского кратона, а восточное - раннепалеозойскими складчатыми и магматическими комплексами. Во внутреннем поле впадины выделяют серию субпараллельных разломов второго порядка, которые оперяют зону основного разлома и способствуют компенсации смещений по нему. Асимметрия геологического строения находит свое отражение и в асимметричном распределении эпицентров землетрясений: основная часть эпицентров землетрясений сосредоточена от линии основного разлома на восток.

Характер реализации сейсмичности исследуемой территории достаточно многообразен: помимо одиночных сильных землетрясений, здесь наблюдаются группы землетрясений, сосредоточенные как во времени (рои и афтершоки), так и в пространстве (кластеры), что говорит о высокой степени структурированности сейсмогенной среды и наличии сейсмоактивных структур [Arefiev, 2003; Shebalin et al., 1991; Sherman et al., 2004]. Также при анализе сейсмичности отмечается наличие брешей в эпицентральном поле, чередование участков повышенной и пониженной плотности эпицентров землетрясений, коррелирующих с блоковой дели- 


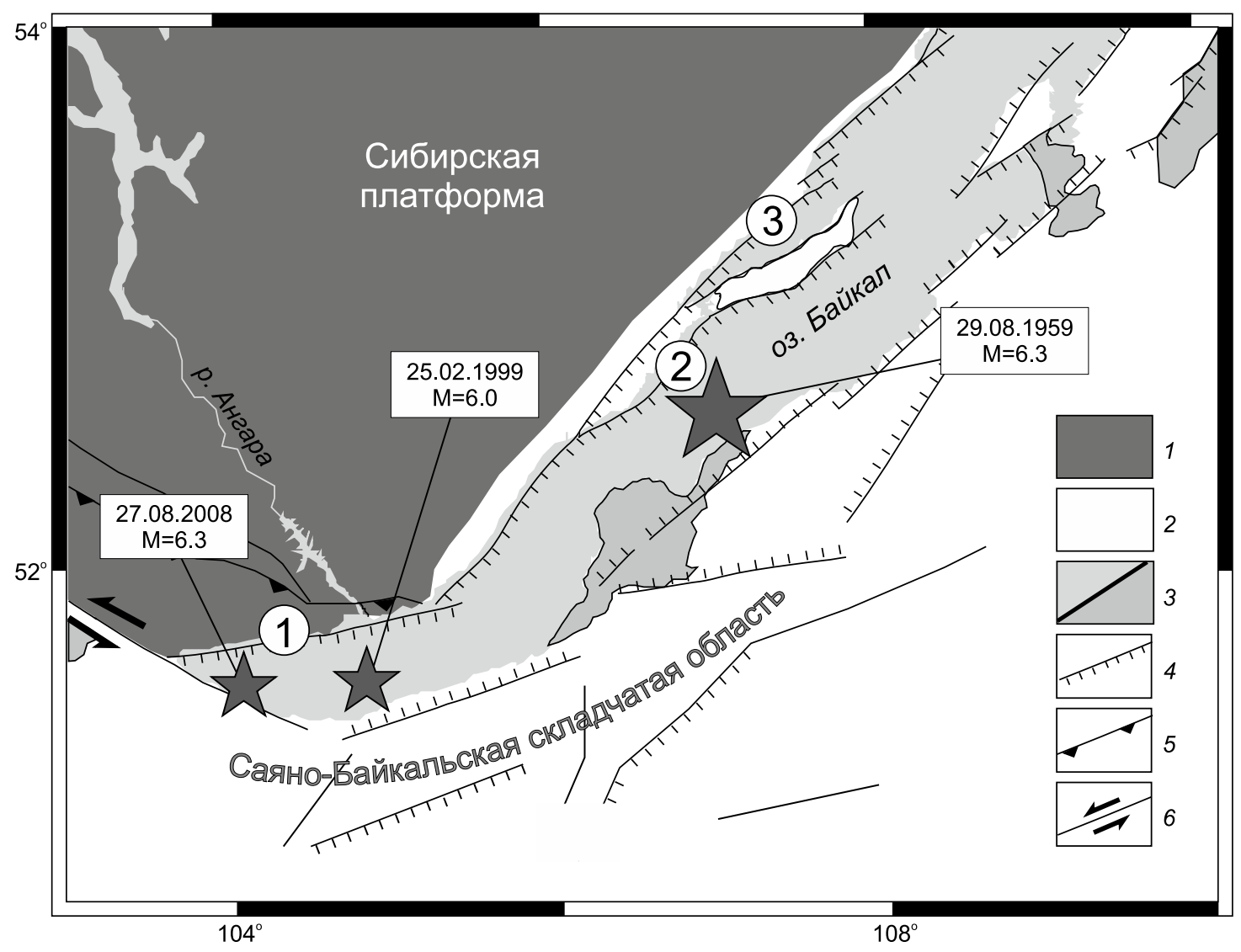

Рис. 1. Схема неотектонических структур Южнобайкальской впадины и ее окружения.

1 - Сибирская платформа; 2 - Саяно-Байкальская складчатая область; 3 - кайнозойские рифтовые впадины; 4-6 - разломы: 4 - сбросы, 5 - взбросы и надвиги, 6 - сдвиги, цифрами в кружках обозначены разломы: 1 - Обручевский, 2 - Морской (Ольхонский), 3 - Приморский. Звездочками показаны эпицентры сильнейших землетрясений исследуемого района: Среднебайкальского (29 августа 1959 г., M=6.3), Южнобайкальского (25 февраля 1999 г., M=6.0) и Култукского (27 августа 2008 г., M=6.3).

Fig. 1. Schematic map of neotectonic structures in the South Baikal basin and adjacent areas.

1 - Siberian platform; 2 - Sayan-Baikal folded area; 3 - Cenozoic rift depressions; 4-6 - faults: 4 -normal, 5 - reverse and thrust, 6 - strikeslip. Numbers in circles: 1 - Obruchev fault, 2 - Morskoy (Olkhon) fault, 3 - Primorsky fault. Asterisks indicate the epicenters of the strongest earthquakes in the study area: Middle Baikal (August 29, 1959, M 6.3), South Baikal (February 25, 1999, M 6.0), and Kultuk (August 27, 2008, M 6.3).

мостью земной коры [Golenetsky, 1976; Solonenko et al., 1997; Zherebtsov, 2012; Radziminovich et al., 2018]. Основная масса землетрясений в районе Южнобайкальской впадины локализуется на глубинах 9-21 км, с максимумом на 14-18 км [Arefiev et al., 2008; Radziminovich, 2010; Suvorov, Tubanov, 2008].

Исследуемый район БРС характеризуется сложным глубинным строением. По данным телесейсмической томографии мощность литосферы под Байкальской впадиной сокращена по сравнению с окружающими регионами: 45-50 км под БРС, 200 км под Сибирской платформой, от 120 до 170 км под Забайкальем [Zorin et al., 1996; Gao et al., 1994]. Мощность коры под рифтовыми впадинами составляет 34-48 км, 37-39 км - под Сибирской платформой и 39-41 км - в Забайкалье [Puzyrev, 1981, 1993; Mats et al., 2001]. Под южным оконча- нием Байкальской впадины расположен выступ аномальной мантии со скоростями $S$-волн $4.25-$ 4.58 км/с [Gao et al., 2003]. Считалось, что под главными рифтовыми впадинами земная кора утонена, хотя, согласно последней интерпретации данных глубинного сейсмического зондирования [Suvorov et al., 2002], это утонение не подтвердилось.

\section{3. МЕтоды}

В работе для детальной оценки параметров затухания сейсмических волн используется комплекс методов: расчет добротности по сейсмической коде $\left(Q_{c}\right)$ с использованием модели однократного рассеяния [Aki, Chouet, 1975], оценка затухания прямых объемных $S$-волн методом нормализации к коде 


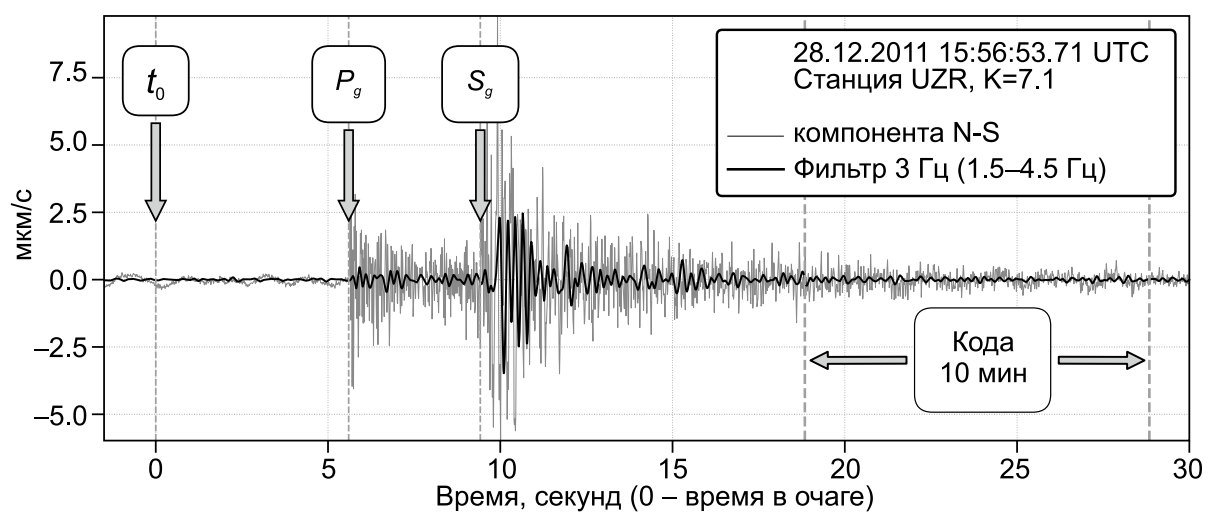

Рис. 2. Пример типичной сейсмограммы локального землетрясения в Южном Байкале (28 декабря 2011 г., энергетический класс $K=7.1$ ), полученной на расстоянии 30 км, станция UZR (Узур), компонента N-S. Cтрелками показано время в очаге и время вступления прямых $P$ - и $S$-волн, пунктирными линиями показан участок коды от момента времени, равного удвоенному времени пробега $S$-волны.

Fig. 2. Typical seismogram for a local earthquake in the South Baikal area (December 28, 2011, energy class $K$ 7.1), which was recorded at a distance of $30 \mathrm{~km}$ by the UZR (Uzur) station, component N-S. Arrows indicate the time in the earthquake source, arrival of direct $P$ - and $S$-waves; dashed lines show the coda segment from the time point that is equal to twice the $S$-wave path.

$[A k i, 1980]$ и разделение общего затухания $Q_{\mathrm{T}}$ на компоненты (рассеяние на неоднородностях среды, $Q_{\mathrm{sc}}$, и вследствие потерь внутренней энергии, $Q_{\mathrm{i}}$ ) методом Веннерберга [Wennerberg, 1993].

В рамках модели однократного рассеяния [Aki, Chouet, 1975] сейсмическая кода рассматривается как суперпозиция объемных волн, отраженных от случайно распределенных в среде неоднородностей. Уменьшение амплитуды коды со временем происходит вследствие затухания энергии и геометрического расхождения и не зависит от характеристик очага землетрясения, эффектов пути и усиления на сейсмостанции [Aki, 1969].

Амплитуда кода-волны $A_{\mathrm{C}}$ в момент времени $t$ от времени в очаге для сейсмограммы, отфильтрованной на центральной частоте $f$, связывается с добротностью следующим соотношением [Aki, Chouet, 1975]:

$$
A(f, t)=S(f) \cdot t^{-\alpha} \cdot e^{\frac{-\pi f t}{Q_{C}(f)}},
$$

где $S(f)$ - временная функция источника, $\alpha$ - характеристика геометрического расхождения. Прологарифмировав (1), получим:

$$
\ln \left\{A(f, t) \cdot t^{\alpha}\right\}=\ln \{S(f)\}-\frac{\pi \cdot f \cdot t}{Q_{C}(f)} .
$$

Наклон графика зависимости $\ln \left\{A(f, t) \cdot t^{\alpha}\right\}$ от времени $t$ определяет значение $Q$ для рассматриваемой частоты $f$. Согласно работе [Rautian, Khalturin, 1978], приведенные выше соотношения действительны для времен бо́льших, чем удвоенное время пробега S-волны, так как для этих времен очаговым процессом можно пренебречь (рис. 2).

Расчет сейсмической добротности по прямым поперечным волнам $\left(Q_{S}\right)$ осуществлялся с использованием модифицированного метода нормализации к коде [Aki, 1980]:

$$
\ln \left[\frac{A_{S}(f, r) r^{\alpha}}{A_{c}\left(f, t_{c}\right)}\right]_{r \pm \Delta r}=-\frac{\pi f}{Q_{S}(f) V_{S}} r+\operatorname{const}(f),
$$

где $A_{S}$ - это спектральная амплитуда прямой $S$-волны на расстоянии $r$; $A_{C}$ - среднее квадратическое значение в выбранном окне; $Q_{S}(f)$ - значение сейсмической добротности для $S$-волн и $V_{S}-$ средняя скорость $S$-волн. Из графика зависимости амплитуды от расстояния можно получить значение $Q_{S}$, используя коэффициент наклона уравнения линейной регрессии.

Для оценки величин добротности $Q_{\mathrm{Sc}}$ и $Q_{\mathrm{i}}$ использовался метод Веннерберга [Wennerberg, 1993], который рассматривает возможность интерпретации значения $Q_{\mathrm{C}}$ в терминах гибридной теории многократного рассеяния [Zeng, 1991]. В основе метода лежит предположение о тождественности затухания, определенного по прямым поперечным $S$-волнам в объеме среды, эквивалентном объему формирования коды, общему затуханию $Q_{\text {T. }}$ Согласно работе [Zeng, 1991], полученное значение $Q_{\mathrm{C}}$ можно представить в виде:

$$
\frac{1}{\mathrm{Q}_{\mathrm{C}}}=\frac{1}{\mathrm{Q}_{\mathrm{i}}}+\frac{1-2 \cdot \delta(\tau)}{\mathrm{Q}_{\mathrm{SC}}},
$$

где $1-2 \cdot \delta(\tau)=\frac{-1.44}{4.44+0.738 \cdot \tau}$ и $\tau=\frac{\omega \cdot \mathrm{W}}{\mathrm{Q}_{\mathrm{SC}}}, W$ - длина окна обработки коды (c), $\omega$ - угловая частота. 


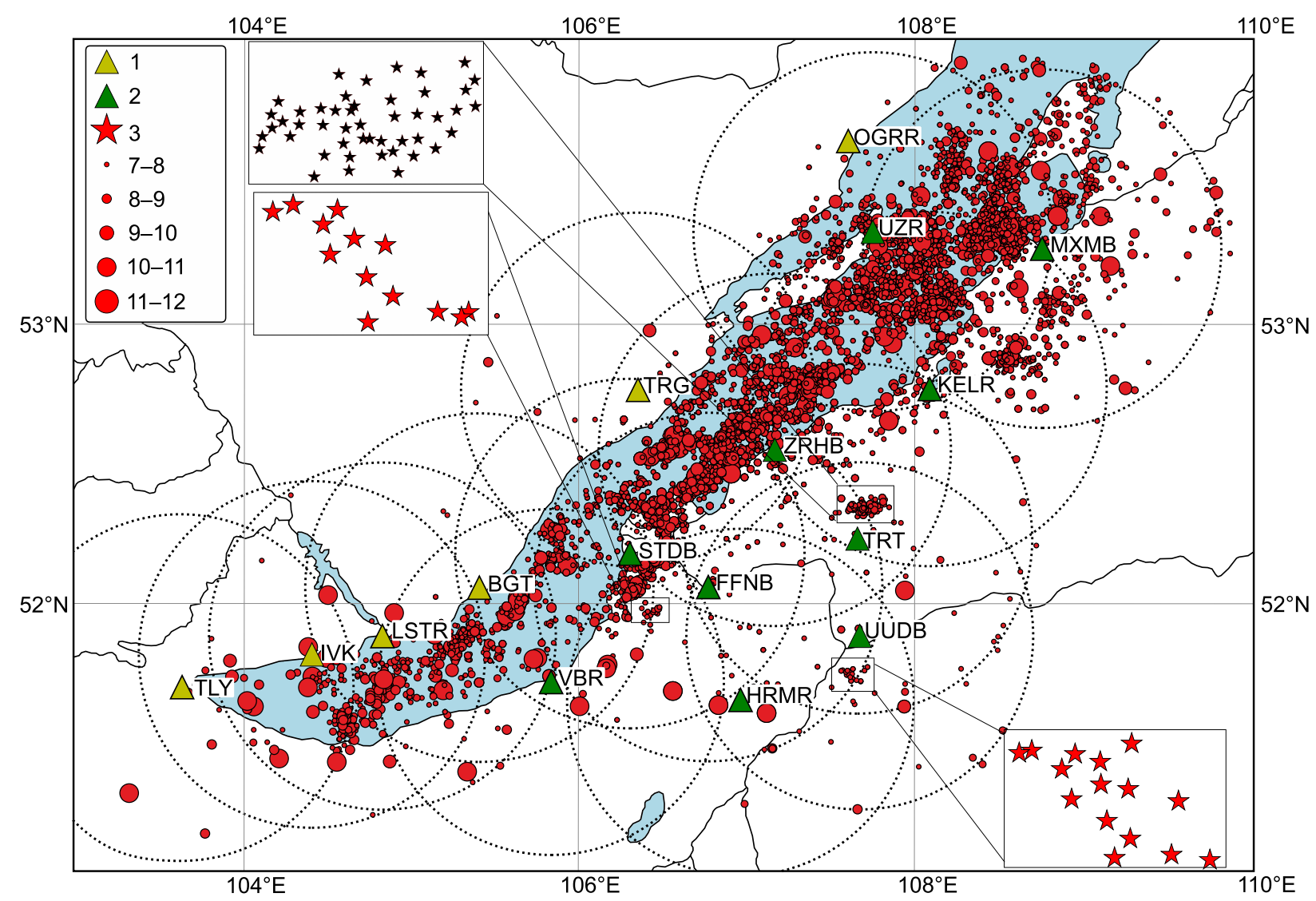

Рис. 3. Карта взаимного расположения сейсмических станций (1 - станции Байкальского и 2 - Бурятского филиала ФИЦ «ЕГС РАН») и эпицентров землетрясений (показаны кружками разного размера в зависимости от энергии события) и промышленных взрывов (3), использованных в настоящей работе. Окружностями для каждой станции показаны области радиусом 70 км. На врезках - эпицентры использованных промышленных взрывов.

Fig. 3. Map showing the locations of seismic stations ( 1 and 2 - stations of the Baikal and Buryatian branches of the Federal Research Center Geophysical Survey of RAS, respectively), earthquake epicenters (circles of different sizes depending on event energy), and industrial explosions (3) mentioned in this article. The radius of the circle areas shown for each station is $70 \mathrm{~km}$. The insets show the epicenters of the industrial explosions.

Значения внутреннего затухания $Q_{\mathrm{i}}$ и рассеяния на неоднородностях $Q_{\mathrm{SC}}$ рассчитываются из величин

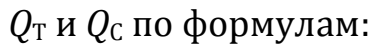

$$
\begin{aligned}
& \frac{1}{\mathrm{Q}_{\mathrm{SC}}}=\frac{1}{2 \cdot \delta(\tau)} \cdot\left(\frac{1}{\mathrm{Q}_{\mathrm{T}}}-\frac{1}{\mathrm{Q}_{\mathrm{C}}(\tau)}\right), \\
& \frac{1}{\mathrm{Q}_{\mathrm{i}}}=\frac{1}{2 \cdot \delta(\tau)} \cdot\left(\frac{1}{\mathrm{Q}_{\mathrm{C}}(\tau)}+\frac{2 \cdot \delta(\tau)-1}{\mathrm{Q}_{\mathrm{T}}}\right) .
\end{aligned}
$$

\section{4. ДАННЫЕ}

В работе использовались записи локальных и региональных сейсмических событий (землетрясений и промышленных взрывов) на территории центральной части БРС, полученные сейсмическими станциями Байкальского и Бурятского филиалов Федерального исследовательского центра «Единая геофизическая служба РАН» (ФИЦ ЕГС
РАН) на расстояниях до 150 км (рис. 3, табл. 1). Использование локальных землетрясений (расстояния до 70 км) позволяет исключить из анализа поверхностные волны, а также при расстояниях между соседними сейсмическими станциями от 50 до 100 км картировать поле затухания сейсмических волн в районе Южнобайкальской впадины и ее окружения. События на эпицентральных расстояниях более 70 км использовались для оценки затухания по прямым волнам.

Всего было обработано 4740 землетрясений с энергетическими классами $K=7-14$, глубины гипоцентров оцениваются в пределах 9-22 км с максимумом 11-16 км. Также для улучшения покрытия территории Забайкалья было выбрано 73 промышленных карьерных взрыва с $K=7-9$ (рис. 3).

Для расчета сейсмической добротности по коде использовалась программа $\operatorname{Cod} a Q$, входящая в состав пакета программ Seisan [Havskov, Ottemoller, 
Т а б л и ц а 1. Сейсмические станции, записи которых использовались для расчета затухания

$\mathrm{T}$ a b l e 1 . Seismic stations that recorded the data used to calculate attenuation

\begin{tabular}{|c|c|c|c|c|c|c|c|}
\hline \multirow[t]{2}{*}{ № } & \multirow[t]{2}{*}{ Название/код } & \multicolumn{2}{|c|}{ Координаты } & \multirow[t]{2}{*}{ Полоса частот, Гц } & \multirow[t]{2}{*}{ Период, годы } & \multirow[t]{2}{*}{$N_{Q \mathrm{c}}$} & \multirow[t]{2}{*}{$N_{Q \mathrm{~s}}$} \\
\hline & & с.ш. & в.д. & & & & \\
\hline 1 & Большое Голоустное/BGT & 52.05 & 105.41 & $0.5-20$ & $2011-2014$ & 34 & 12 \\
\hline 2 & Ивановка/IVK & 51.8 & 104.41 & $0.5-20$ & 2011-2014 & 10 & 36 \\
\hline 3 & Листвянка/LSTR & 51.87 & 104.83 & $0.5-20$ & 2004-2014 & 153 & 246 \\
\hline 4 & Онгурены/OGRR & 53.64 & 107.56 & $0.5-20$ & 2004-2014 & 471 & 414 \\
\hline 5 & Тырган/TRG & 52.76 & 106.35 & $0.5-20$ & $2001-2014$ & 998 & 119 \\
\hline 6 & Талая/TLY & 51.68 & 103.64 & $0.03-10$ & 1999-2014 & 33 & 16 \\
\hline 7 & Бабушкин/ВТМ & 51.7 & 105.83 & $0.5-20$ & $2001-2007$ & 22 & 20 \\
\hline 8 & Заречье/ZRHB & 52.55 & 107.16 & $0.5-20$ & $2001-2014$ & 450 & 374 \\
\hline 9 & Котокель/KELR & 52.76 & 108.08 & $0.5-20$ & $2005-2014$ & 121 & 178 \\
\hline 10 & Максимиха/МХМВ & 53.26 & 108.74 & $0.5-20$ & $2001-2014$ & 667 & 369 \\
\hline 11 & Степной Дворец/STDB & 52.17 & 106.36 & $0.5-20$ & 2001-2014 & 291 & 100 \\
\hline 12 & Турунтаево/TRT & 52.22 & 107.65 & $0.5-20$ & 2001-2008 & 790 & 315 \\
\hline 13 & Узур/UZR & 53.32 & 107.74 & $0.5-20$ & $2011-2014$ & 243 & 45 \\
\hline 14 & Улан-Удэ/UUDB & 51.87 & 107.66 & $0.5-20$ & $2001-2014$ & 25 & 20 \\
\hline 15 & Фофоново/FFNB & 52.05 & 106.76 & $0.5-20$ & 2001-2014 & 409 & 512 \\
\hline 16 & Хурамша/HRMR & 51.63 & 106.95 & $0.5-20$ & $2001-2014$ & 13 & 14 \\
\hline
\end{tabular}

П р и м е ч а н и е. Станции 1-6 входят в сеть Байкальского филиала ФИЦ ЕГС РАН, станции 7-16 - Бурятского филиала ФИЦ ЕГС PAН; для каждой станции указан временной период, за который выбирались сейсмограммы для анализа; $N_{Q c}$ и $N_{Q s}-$ количество обработанных сейсмограмм для расчета добротности по коде и прямым $S$-волнам соответственно.

$\mathrm{N}$ o t e. Stations 1-6 and stations 7-16 - stations of the Baikal and Buryatian branches of the Federal Research Center Geophysical Survey of RAS, respectively. For each station, the periods of time for the seismograms selected for analysis are indicated. $N_{Q c}$ and $N_{Q s}-$ number of seismograms processed for calculating the seismic quality factors from coda and direct $S$-waves, respectively.

2003]. Для обработки выбирались записи с соотношением сигнал-шум $S / N>4$, начало окна обработки коды $(W)$ равно удвоенному времени пробега $S$-волны, длина $W$ бралась равной 10, 20, 30 и 40 с. Оценка добротности выполнялась для шести частотных диапазонов: $0.75 \pm 0.25,1.0 \pm 0.5,1.5 \pm 0.5$, $3.0 \pm 1.5,6 \pm 3$ и $12 \pm 6$ Гц. При расчетах показатель геометрического расхождения $\alpha$ принимался равным 1 , исходя из предположения о том, что кода представляет собой рассеянные поперечные волны [Sato, Fehler, 1998], средняя скорость $S$-волны $V_{S}=$ $=3.51 \mathrm{kм} / \mathrm{c}$ [Tubanov et al., 2013]. Для расчета $Q$ по прямым волнам использовались те же параметры, за исключением выбора участка записи для обработки сигнала: началом считался момент вступления прямой $S$-волны, длина отрезка составляла 10 с. Расчеты осуществлялись в программе CodaNorm, разработанной авторами ранее [Predein et al., 2017].

\section{5. РЕЗУЛЬТАТЫ}

В результате для Южнобайкальской впадины и прилегающих территорий получены значения сейсмической добротности по прямым поперечным волнам и их коде в частотном диапазоне от 0.5 до

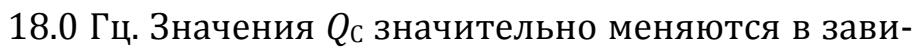
симости от частоты и длины окна, выбранной для обработки коды: от $57 \pm 28$ (центральная частота $f_{\mathrm{C}}=0.75$ Гц $)$ и $571 \pm 108 \quad\left(f_{\mathrm{C}}=12\right.$ Гц $)$ для длины окна $W=10$ с и до $141 \pm 46\left(f_{\mathrm{C}}=0.75\right.$ Гц) и $1579 \pm 294$ $\left(f_{c}=12\right.$ Гц) для $W=40$ с. На базе полученных величин

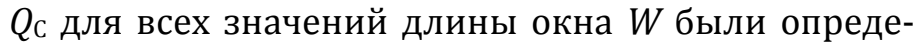
лены эмпирические зависимости добротности от частоты (табл. 2, рис. 4) согласно степенному законy [Mitchell, 1981]:

$$
Q(f)=Q_{0} \cdot f^{n}
$$

где $Q(f)$ - сейсмическая добротность, $Q_{0}$ - добротность на некоторой референтной частоте $f_{0}$ (как правило, $f_{0}=1$ Гц) и $n$ - показатель зависимости добротности от частоты, или частотный параметр.

Для сейсмической станции UUDB из-за недостаточного количества сейсмических событий на эпицентральных расстояниях до 70 км для длины окна 30 с не было получено устойчивого результата для центральных частот 1.5 и 3.0 Гц и для $W=40$ с - для частот до 6 Гц, в связи с чем для этих окон не были определены эмпирические соотношения $Q_{\mathrm{c}}(f)$ (табл. 2, рис. 4).

Значения $Q_{\mathrm{s}}$ также показывают значительные вариации в зависимости от частоты: от $13\left(f_{\mathrm{c}}=0.75\right.$ Гц) до $280\left(f_{\mathrm{c}}=12\right.$ Гц) для сейсмической станции Степной Дворец (STDB) и до $42\left(f_{\mathrm{c}}=0.75\right.$ Гц) и 958 $\left(f_{\mathrm{C}}=12\right.$ Гц) для станции Турунтаево (TRT) (табл. 3). Зависимости добротности от частоты по прямым 
A.A. Dobrynina et al.: Spatial variations of seismic wave attenuation...

T а б л и ц а 2 . Эмпирическая зависимость сейсмической добротности $Q_{\mathrm{C}}$ от частоты для разных значений длины окна $W$ для станций региона

$\mathrm{T}$ a b l e 2. Empirical dependence of seismic quality factor $\boldsymbol{Q}_{\mathrm{c}}$ on frequency for different values of window length $W$ for different stations

\begin{tabular}{|c|c|c|c|c|c|c|c|c|}
\hline \multirow[t]{2}{*}{ Код станции } & \multicolumn{2}{|l|}{$10 \mathrm{c}$} & \multicolumn{2}{|l|}{$20 \mathrm{c}$} & \multicolumn{2}{|l|}{$30 \mathrm{c}$} & \multicolumn{2}{|l|}{$40 \mathrm{c}$} \\
\hline & $Q_{0}$ & $n$ & $Q_{0}$ & $n$ & $Q_{0}$ & $n$ & $Q_{0}$ & $n$ \\
\hline BGT & $63 \pm 6$ & $0.85 \pm 0.06$ & $110 \pm 8$ & $0.91 \pm 0.04$ & $149 \pm 5$ & $0.84 \pm 0.06$ & $169 \pm 8$ & $0.92 \pm 0.03$ \\
\hline LSTR & $54 \pm 3$ & $0.96 \pm 0.04$ & $87 \pm 4$ & $0.91 \pm 0.03$ & $121 \pm 7$ & $0.96 \pm 0.03$ & $118 \pm 23$ & $0.99 \pm 0.08$ \\
\hline OGRR & $63 \pm 2$ & $0.92 \pm 0.02$ & $105 \pm 3$ & $0.98 \pm 0.01$ & $148 \pm 11$ & $0.98 \pm 0.03$ & $216 \pm 37$ & $0.89 \pm 0.07$ \\
\hline TRG & $63 \pm 4$ & $0.88 \pm 0.04$ & $102 \pm 5$ & $0.96 \pm 0.03$ & $131 \pm 8$ & $0.98 \pm 0.03$ & $164 \pm 17$ & $0.95 \pm 0.05$ \\
\hline BTM & $66 \pm 7$ & $0.86 \pm 0.11$ & $108 \pm 7$ & $0.93 \pm 0.03$ & $139 \pm 9$ & $0.96 \pm 0.03$ & $182 \pm 18$ & $0.93 \pm 0.05$ \\
\hline ZRHB & $65 \pm 7$ & $0.81 \pm 0.07$ & $94 \pm 17$ & $0.92 \pm 0.1$ & $104 \pm 30$ & $0.97 \pm 0.14$ & $161 \pm 29$ & $0.91 \pm 0.01$ \\
\hline KELR & $58 \pm 4$ & $0.92 \pm 0.05$ & $92 \pm 8$ & $0.98 \pm 0.04$ & $134 \pm 19$ & $0.94 \pm 0.07$ & $194 \pm 30$ & $0.85 \pm 0.08$ \\
\hline MXMB & $58 \pm 3$ & $0.88 \pm 0.03$ & $93 \pm 4$ & $0.93 \pm 0.03$ & $130 \pm 10$ & $0.93 \pm 0.04$ & $173 \pm 20$ & $0.87 \pm 0.06$ \\
\hline STDB & $77 \pm 1$ & $0.71 \pm 0.01$ & $112 \pm 27$ & $0.73 \pm 0.11$ & $139 \pm 53$ & $0.73 \pm 0.18$ & $144 \pm 50$ & $0.75 \pm 0.16$ \\
\hline TRT & $55 \pm 2$ & $0.96 \pm 0.02$ & $83 \pm 6$ & $1.02 \pm 0.04$ & $114 \pm 15$ & $0.95 \pm 0.06$ & $156 \pm 35$ & $0.86 \pm 0.1$ \\
\hline HRMR & $62 \pm 2$ & $0.91 \pm 0.02$ & $102 \pm 3$ & $0.95 \pm 0.02$ & $148 \pm 11$ & $0.91 \pm 0.05$ & $215 \pm 30$ & $0.82 \pm 0.07$ \\
\hline
\end{tabular}

П р и м е ч а н и е. Для каждого значения показана величина среднеквадратичного отклонения.

$\mathrm{N}$ o t e. A standard deviation is shown for each value.
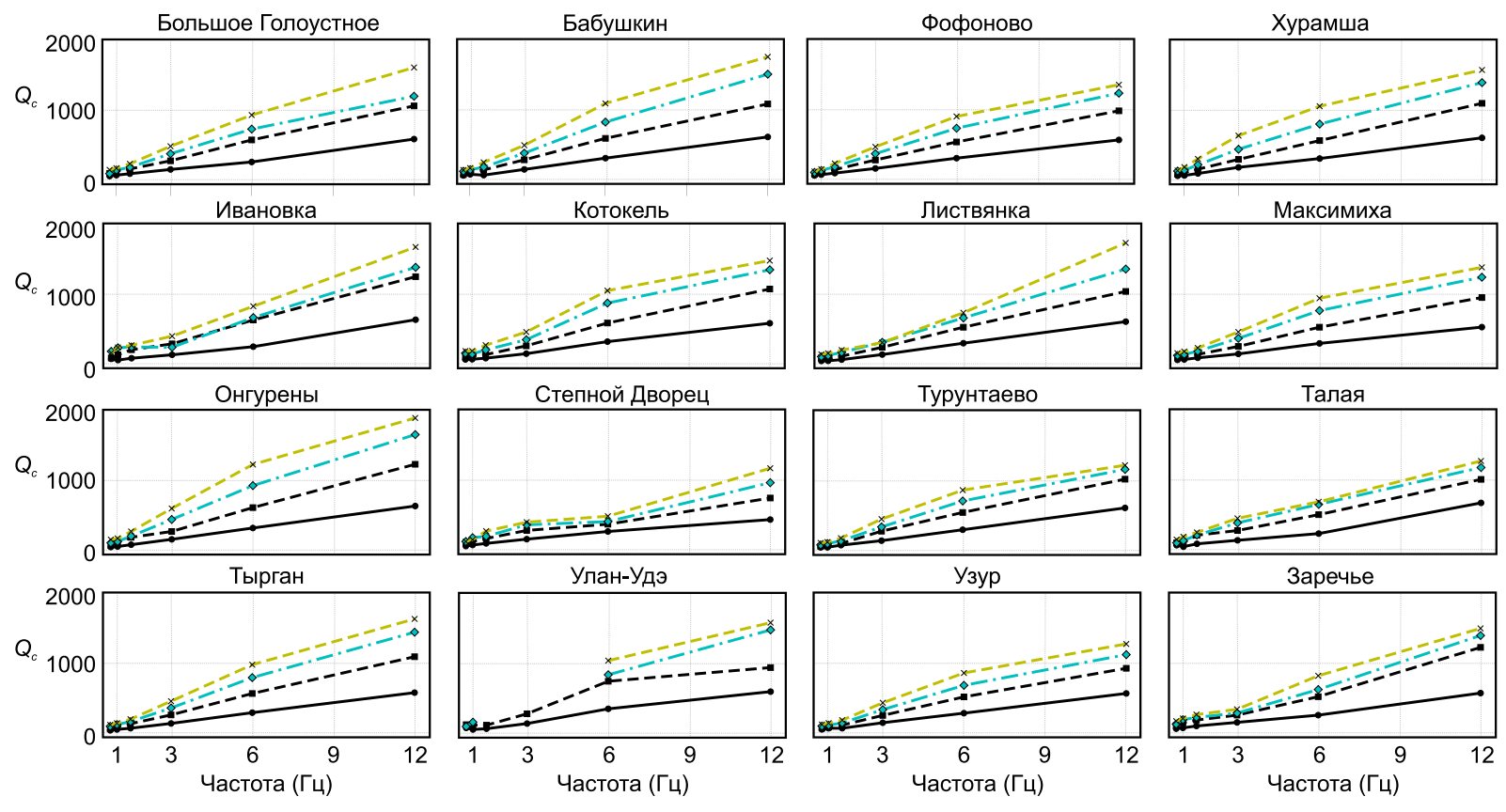

$$
\begin{array}{llll}
\rightarrow-10 c & -\rightarrow 20 c & -\rightarrow-30 c & -*-40 c \\
\hline
\end{array}
$$

Рис. 4. Зависимость сейсмической добротности $Q_{C}$ от частоты и длины окна обработки коды для разных станций.

Fig. 4. Dependence of seismic quality factor $Q_{\mathrm{C}}$ on the frequency and length of the coda processing window for different stations. 
T а б л и ц а 3 . Значения добротности $Q_{s}$ для разных станций

$\mathrm{T}$ a b l e 3 . Values of seismic quality factor $\boldsymbol{Q}_{\mathbf{s}}$ for different stations

\begin{tabular}{|c|c|c|c|c|c|c|c|c|c|}
\hline \multirow[t]{2}{*}{ Код станции } & \multicolumn{6}{|c|}{ Центральная частота, Гц } & \multirow[t]{2}{*}{ Qso } & \multirow[t]{2}{*}{$n$} & \multirow[t]{2}{*}{$N$} \\
\hline & 0.75 & 1 & 1.5 & 3 & 6 & 12 & & & \\
\hline TRG & 27.23 & 38.18 & 65.35 & 161.07 & 403.88 & 921.94 & 43.0 & 1.23 & 119 \\
\hline UZR & 14.43 & 20.03 & 32.53 & 72.35 & 194.26 & 436.80 & 20.6 & 1.23 & 45 \\
\hline BGT & 27.68 & 44.92 & 50.11 & 82.38 & 309.63 & 916.60 & 18.5 & 1.57 & 12 \\
\hline $\mathrm{IVK}^{*}$ & 45 & 79.55 & 132.54 & 358.94 & 525.30 & 745.83 & 128.2 & 0.73 & 36 \\
\hline LSTR & 25.52 & 28.65 & 36.01 & 116.13 & 309.04 & 791.15 & 26.1 & 1.37 & 246 \\
\hline KELR & 20.53 & 35.87 & 69.68 & 156.58 & 248.53 & 501.82 & 46.6 & 0.96 & 178 \\
\hline MXMB & 37.60 & 43.32 & 65.15 & 102.14 & 268.41 & 582.84 & 35.0 & 1.13 & 369 \\
\hline STDB & 13.06 & 17.60 & 26.86 & 63.26 & 144.77 & 279.86 & 20.7 & 1.05 & 100 \\
\hline TRT & 42.38 & 53.05 & 71.91 & 143.74 & 348.74 & 958.20 & 31.6 & 1.37 & 315 \\
\hline TLY & 13.75 & 24.25 & 63.56 & 87.00 & 246.35 & - & 25.4 & 1.27 & 12 \\
\hline HRMR & 20.03 & 41.23 & 72.21 & 103.97 & 236.04 & 451.50 & 39.5 & 0.98 & 14 \\
\hline
\end{tabular}

П р и м е ч а н и е. $N$ - количество сейсмограмм, по которым получены значения $Q_{S}, Q_{S 0} ; n-$ расчетные значения $Q_{S}$ на частоте 1 Гц и показатель зависимости $Q$ S от частоты для каждой станции. Для станции IVK (обозначена звездочкой - *) значения добротности получены для окна длиной 5 с.

N o t e. $N$ - number of seismograms used to calculate the values of $Q_{s}$ and $Q_{s 0} ; n$ - calculated values of $Q_{s}$ at $1 \mathrm{~Hz}$, and the rate of $Q_{s}$ dependence on the frequency for each station. For station IVK (indicated by ${ }^{*}$ ), the seismic quality values were obtained for a window of $5 \mathrm{sec}$.

волнам для всех станций также определялись по формуле (5) (табл. 3). По виду полученной эмпирической кривой все станции можно разделить на че- тыре основных группы, отличающиеся значениями частотного параметра и максимальными величинами $Q$ (рис. 5).
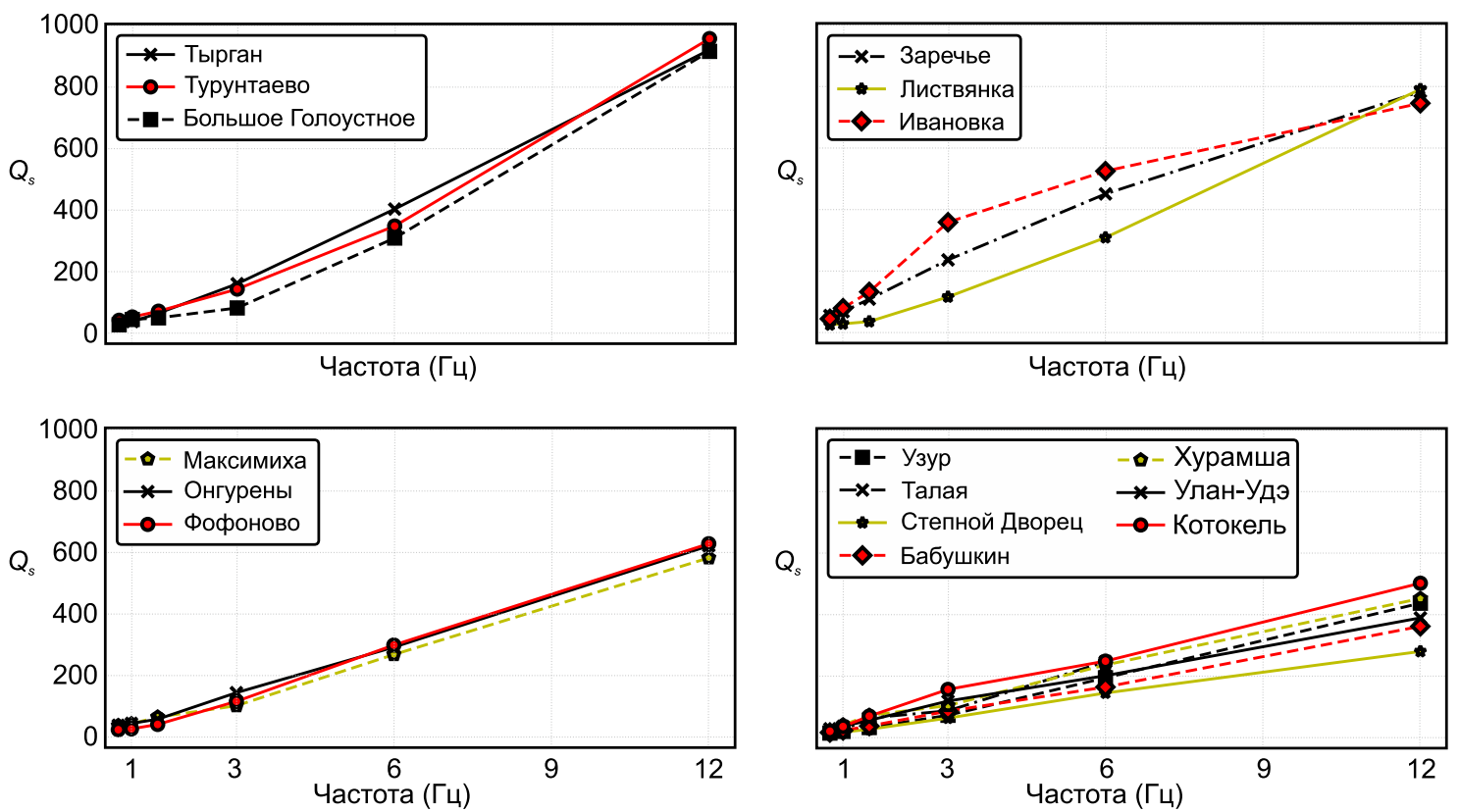

Рис. 5. Зависимость сейсмической добротности $Q_{\mathrm{S}}$ от частоты для разных станций.

Fig. 5. Dependence of seismic quality factor $Q_{S}$ on the frequency for different stations. 
Значения сейсмической добротности $Q_{\mathrm{S}}$ и $Q_{\mathrm{C}}$ также использовались для оценки вклада компонент затухания - внутреннего затухания $Q_{\mathrm{i}}$ и рассеяния на неоднородностях среды $Q_{s c}$ - в общее затухание, согласно подходу [Wennerberg, 1993]. При этом значение общего затухания принималось равным $Q_{s}$, а значения $Q_{\mathrm{i}}$ и $Q_{\mathrm{Sc}}$ определялись по формулам (3-4). Необходимо отметить, что для расчетов использовались значения затухания по прямым, полученные на тех же расстояниях, что и значения для добротности по коде, - до 70 км от эпицентра. Полученные величины компонент затухания приведены в таблице 4.

\section{6. ОБСУЖДЕНИЕ РЕЗУЛЬТАТОВ}

Значения сейсмической добротности $Q_{c}$, полученные в настоящей работе, сопоставимы с величинами $Q_{C}$, характерными для тектонически активных регионов мира [Aki, 1981; Sato, Fehler, 1998; Mak et al., 2004], и хорошо согласуются с данными, полученными авторами ранее для Южнобайкальской впадины: $Q_{\mathrm{C}}(f)=(95 \pm 11) \cdot f(0.89 \pm 0.08) \quad$ [Dobrynina et al., 2011, 2016a, 2016b]. Значения добротности по прямым поперечным волнам для станций Турунтаево и Хурамша также хорошо согласуются с предварительными определениями $Q_{\mathrm{S}}$ [Dobrynina et al., 2016a].

Основной целью данной работы являлась оценка латеральных вариаций затухания сейсмических волн для Южнобайкальской впадины и ее окружения и их сопоставление с геолого-геофизическими параметрами среды: энергией и плотностью землетрясений, тепловым потоком, плотностью разломов и геологическим строением района. Для этого расчеты сейсмической добротности проводились для каждой сейсмической станции отдельно с использованием событий, локализованных на расстояниях до 70 км (для определений по коде) и до 150 км (для прямых $S$-волн). Полученные значения $Q$ использовались для построения двумерных карт сейсмической добротности и коэффициента затухания рассматриваемого региона. Коэффициенты затухания $\delta$ оценивались для каждого значения $W$ согласно:

$$
\delta=\frac{\pi \cdot f}{V \cdot Q}
$$

где $V$ - скорость сейсмических волн.

Двумерное картирование региона по параметрам затухания было выполнено согласно методу перекрывающихся эллипсов [Mitchell et al., 2008], реализованному авторами в программе « $2 D$ Quality». В основе метода лежит предположение о том, что значение $Q$, полученное на сейсмической станции, характеризует объем пространства (эллипсоид), в фокусах которого находятся источник и приемник [Pulli, 1984]. Исследуемый регион разбивается на ячейки, и среднее значение затухания в каждой ячейке определяется из величин $Q$, соответствующих эллипсоидам, перекрывающим эту ячейку. Размеры проекции эллипсоида на земную поверхность ( $a, b$ - длина полуосей эллипсоида) определяются соотношениями:

$$
a=\frac{V t}{2} ; b=\sqrt{\left(\frac{V t}{2}\right)^{2}-\frac{r^{2}}{4}}
$$

где $V$ - скорость сейсмических волн, $r$ - расстояние «источник - приемник», $t$ - средняя длина временного окна:

$$
t=t_{\text {start }}+\frac{W}{2}
$$

где $t_{\text {start }}$ - начальное время обработки сигнала.

Карты латеральных вариаций параметров затухания строились предварительно для ячеек размерами $0.10^{\circ} \times 0.10^{\circ}, 0.08^{\circ} \times 0.08^{\circ}, 0.05^{\circ} \times 0.05^{\circ}$, в итоге были выбраны карты с размерами $0.08^{\circ} \times 0.08^{\circ}$, как наиболее удобные для анализа (рис. 6).

Анализ пространственных вариаций затухания на разных частотах показывает мозаичное распределение параметра сейсмической добротности и коэффициента затухания в пределах рассматриваемого региона - области с высоким затуханием чередуются со сравнительно узкими районами со слабым затуханием. В Южнобайкальской впадине наибольшее затухание кода-волн наблюдается в Култукской депрессии, в районе дельты р. Селенги и в северной оконечности Южнобайкальской впадины. Локальные области пониженного затухания, отделяющие эти районы, наблюдаются на всех частотах (рис. 6). Для прямых $S$-волн область пониженного затухания распространена более широко и занимает всю центральную часть Южнобайкальской впадины, сливаясь с такими же областями, расположенными на Сибирской платформе и в Забайкалье (рис. 7).

Отчетливо выявляется поперечная зональность распределения параметров затухания сейсмических волн от Сибирской платформы на юго-восток с минимумами затухания в пределах платформы и максимумом в пределах впадины с новым повышением в сторону Забайкалья. Пространственное положение областей повышенного и пониженного затухания в Южнобайкальской впадине может определяться различиями в свойствах земной коры и верхней мантии. По данным [Mats et al., 2001], плотность верхней коры под южной частью Южнобайкальской впадины существенно ниже, чем 

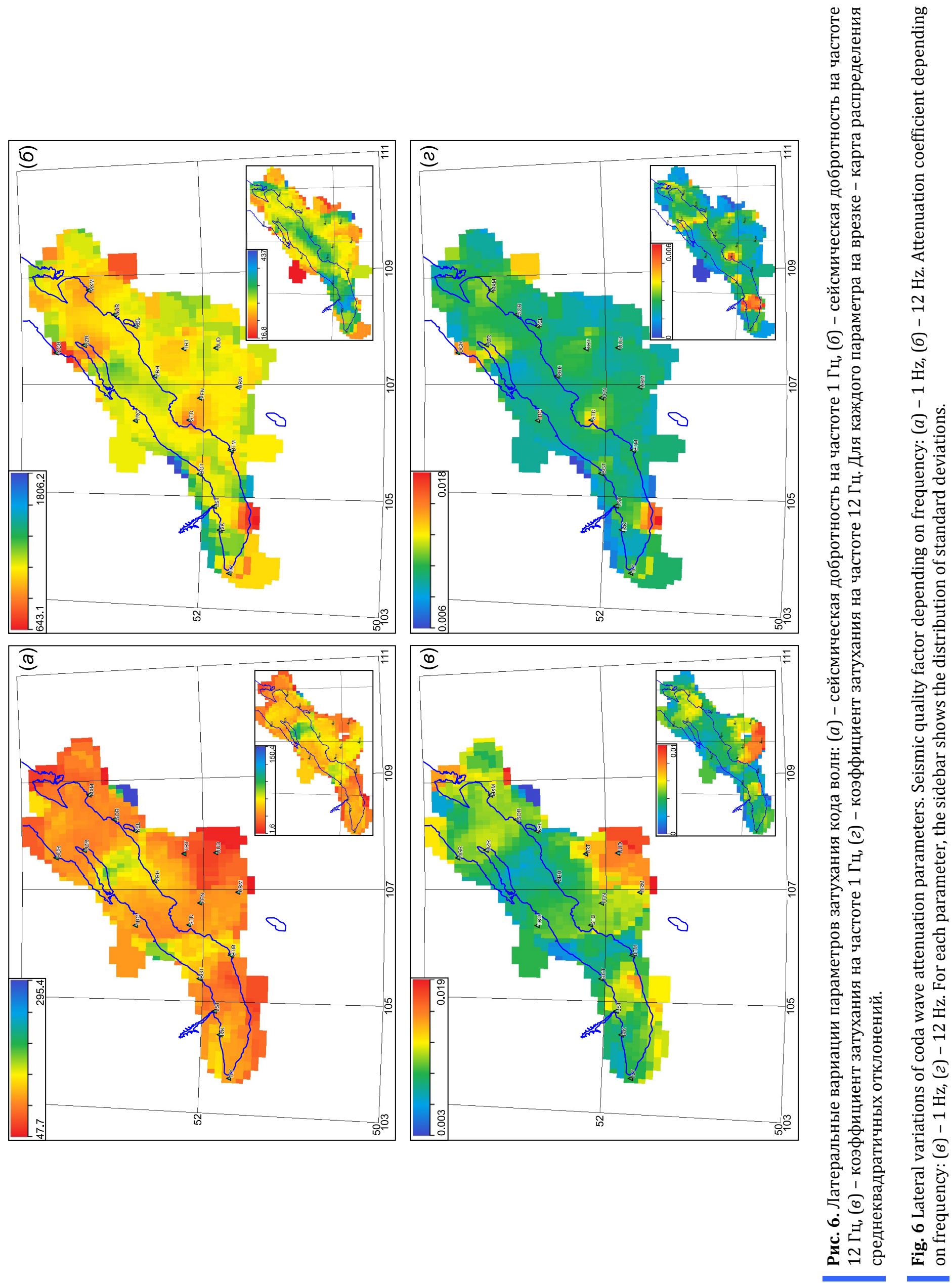

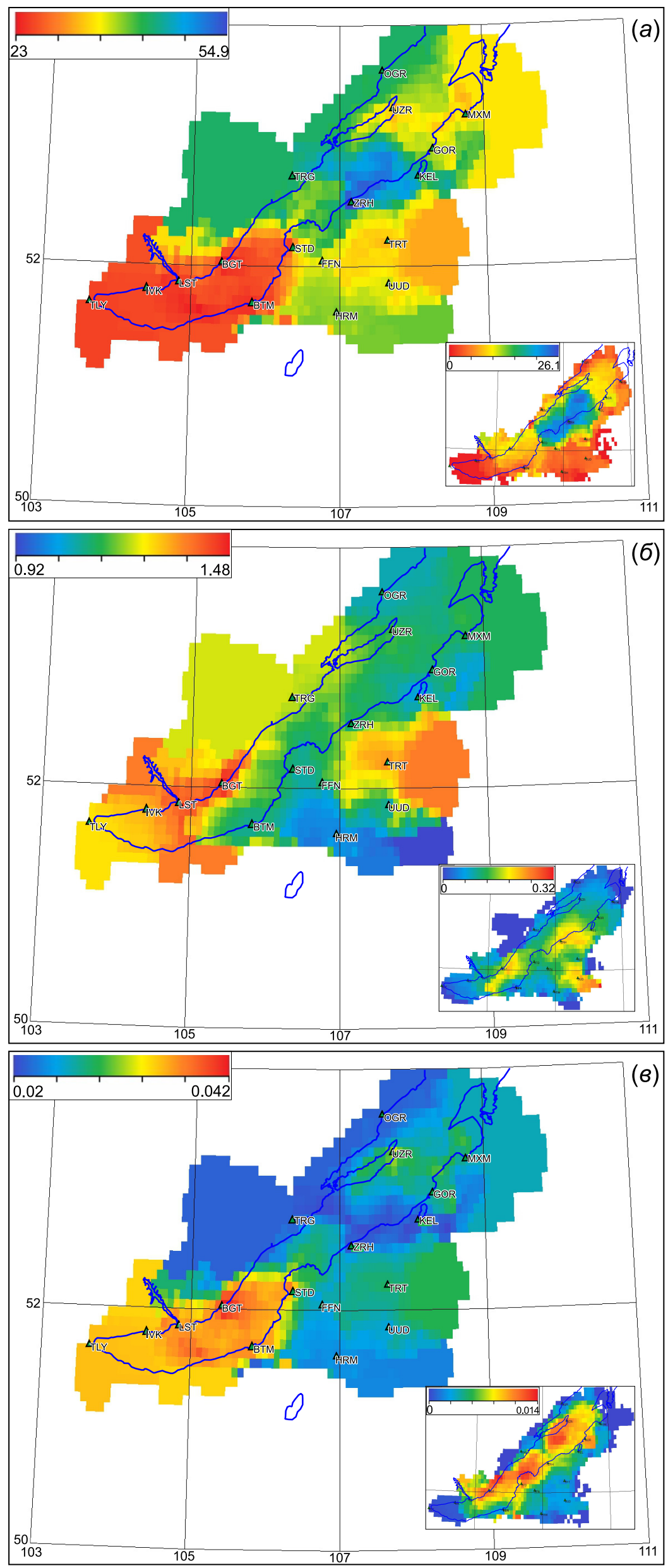

Рис. 7. Латеральные вариации параметров затухания объемных поперечных волн: $(a)$ - сейсмическая добротность на частоте 1 Гц, (б) частотный параметр, (в) - коэффициент затухания. Для каждого параметра на врезке показана карта распределения среднеквадратичных отклонений.

Fig. 7. Lateral variations of attenuation parameters of body shear waves: $(a)$ - seismic quality factor for $1 \mathrm{~Hz}$ frequency, (б) - frequency, ( 8 ) - attenuation coefficient. For each parameter, the sidebar shows the distribution of standard deviations. 
под северной. С другой стороны, под южной частью Байкальской впадины по данным сейсмотомографии выявлен выступ аномальной мантии [Gao et al., 2003], который не прослеживается под остальной частью впадины. Воздействие аномального вещества мантии могло проявиться во флюидизации земной коры и верхней мантии под южной частью Южнобайкальской впадины, что, по-видимому, и привело к увеличению затухания сейсмических волн в этой области.

Результаты более ранних исследований затухания сейсмических волн в литосфере юго-западного фланга Байкальской рифтовой системы [Dobrynina, 2011; Dobrynina et al., 2011, 2016a, 2016b, 2017] выявили зависимость затухания от сейсмической активности и теплового потока и, в меньшей степени, от плотности разломов и возраста консолидации коры. Необходимо отметить, что в указанных работах расчеты параметров затухания сейсмических волн и их сопоставление с геолого-геофизическими характеристиками проводились для отдельных структурных единиц (рифтовых впадин, горных поднятий, межвпадинных перемычек и пр.) и не отличались такой детальностью, как в настоящей работе. Применение подхода перекрывающихся эллипсов к картированию поля затухания сейсмических волн позволяет провести более точный сравнительный анализ.

Сопоставление карт кумулятивной сейсмической энергии, плотности эпицентров землетрясений [Radziminovich et al., 2018], поверхностной плотности разломов [Sherman, 1992] и теплового потока [Duchkov, 1985; Lysak, 2002; Golubev, 2007] показывает хорошую общую сходимость аномалий: области с высокой сейсмической активностью характеризуются высокой плотностью разломов и высокими значениями теплового потока (рис. 8). Области пониженной плотности эпицентров землетрясений и пониженной поверхностной плотности разломов в Южнобайкальской впадине (рис. 8) хорошо согласуются с зонами низкого затухания сейсмических волн (см. рис. 6), а области повышенного затухания совпадают с областями максимальных выделений сейсмической энергии.

Сравнение карт поля затухания по прямым $\mathrm{S}$-волнам и коде в целом показывает хорошее совпадение областей повышенного и пониженного затухания сейсмических волн по всей исследуемой территории за исключением локального района близ северной оконечности Южнобайкальской впадины (станция Онгурены). В отличие от распределения $Q$ по S-волнам, для коды здесь наблюдается локальный максимум затухания, совпадающий с положением локальной аномалии теплового потока (рис. 8, в). При этом поверхностная плотность разломов здесь относительно невелика, а уровень сейсмической активности заметно ниже, чем в остальной части впадины. Можно предположить, что различие в затухании S-волн и коды свидетельствует о большей чувствительности рассеянных волн к степени разогрева земных недр, сопровождающегося дополнительной флюидизацией среды по сравнению с прямыми волнами.

В целом, на всей исследуемой территории для частотного параметра и коэффициента затухания $S$-волн наблюдается прямая зависимость, за исключением локального района Забайкалья в юговосточной части исследуемого региона, близ станций UUDB, HRMR и TRT (cм. рис. 7). В этом районе наблюдается повышенное затухание как для $S$-волн, так и для коды. Здесь, в отличие от остальной рассматриваемой области, в качестве источников сейсмических волн анализировались не только землетрясения, но также промышленные карьерные взрывы.

Интересно, что наиболее ярко эффект повышенного затухания проявляется для низких частот ( $<1.5$ Гц), а также для более длинных окон обработки коды. В работе [Dobrynina, German, 2016] с целью уточнения критериев дискриминации землетрясений и взрывов для района Восточно-Бейского угольного разреза проводился сравнительный анализ спектральных характеристик слабых землетрясений и взрывов. Согласно полученным закономерностям, промышленные взрывы характеризуются максимумом излучения в области низких частот ( $<1$ Гц) в отличие от слабых землетрясений, а также более быстрым спадом амплитуды коды со временем, что соответствует полученным в настоящей работе результатам. Также при сравнительном анализе затухания сейсмических волн от землетрясений, произошедших на разных глубинах (верхняя и средняя кора), показано, что наибольшее затухание наблюдается при локализации очагов землетрясений в верхней коре (глубина 23 км) по сравнению со средней при прочих равных условиях [Dobrynina et al., 2017]. Другими словами, верхняя часть коры максимально неоднородна, и положение гипоцентра источника оказывает существенное влияние на результаты оценки затухания сейсмических волн [Spudich, Iida, 1993; Gusev, 1995].

Таким образом, в нашем случае повышенное затухание сейсмических волн в Забайкалье объясняется двумя факторами: спектральным составом колебаний и поверхностной глубиной взрывов. В целом, при известных фоновых региональных значениях сейсмической добротности резкое увеличение затухания может использоваться в качестве одного из критериев дискриминации слабых землетрясений и промышленных взрывов.

Оценки сейсмической добротности как по прямым волнам, так и по коде показывают сильную 

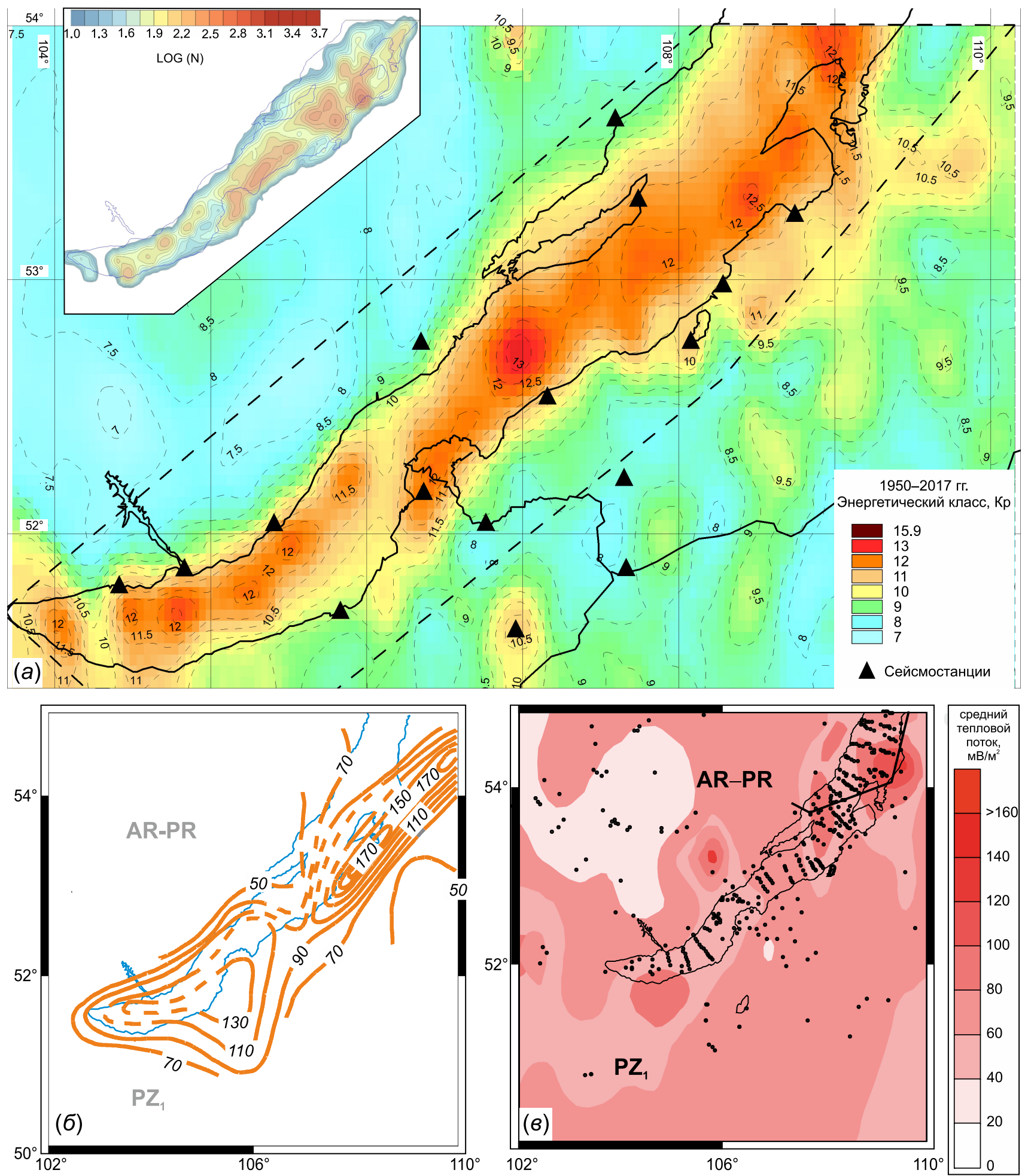

Рис. 8. Распределение суммарной сейсмической энергии за период 1950-2017 гг. (a), поверхностной плотности разломов (по данным [Sherman, 1992]) (б)и среднего теплового потока (по данным [Duchkov, 1985; Lysak, 2002; Golu$b e v, 2007])(8)$, в Южнобайкальской впадине и окружающих территориях. На врезке вверху - карта плотности эпицентров землетрясений за 2003-2014 гг. с K $\geq 6.0$ из работы [Radziminovich et al., 2018]. На карте плотности разломов цифрами показано количество разломов на единицу площади (трапеция с размерами $65 \times 70$ км).

Fig. 8. Schematic maps of the South Baikal basin and adjacent areas: (a) - distribution of the total seismic energy in 19502017; (6) - surface density of faults (number of faults per unit area given by a 65×70 km trapezium) [Sherman, 1992]; (8) mean heat flow [Duchkov, 1985; Lysak, 2002; Golubev, 2007]. Inset - map showing the density of earthquake epicenters in

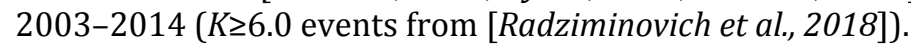


T а б л и ц а 4 . Значения компонент затухания $Q_{\mathrm{i}}$ и $Q_{\mathrm{sc}}$ и их вклад в общее затухание на частоте 1 Гц для разных станций, в процентах

T a b l e 4 . Values of attenuation components $\boldsymbol{Q}_{\mathrm{i}}$ and $\boldsymbol{Q}_{\mathrm{sc}}$, and their contributions (\%) to the total attenuation at $1 \mathrm{~Hz}$ for different stations

\begin{tabular}{lllll}
\hline Код станции & $Q_{\mathrm{i}}$ & $Q_{\mathrm{sc}}$ & $Q_{\mathrm{i}}, \%$ & $Q_{\mathrm{sc}} \%$ \\
\hline TRG & 58.8 & 108.9 & 65 & 35 \\
ZRHB & 68.8 & 6255.6 & 99 & 1 \\
LSTR & 47.3 & 72.7 & 61 & 25 \\
OGRR & 59.4 & 181.1 & 75 & 47 \\
FFNB & 50.7 & 57.2 & 53 & 34 \\
KELR & 54.3 & 105.7 & 66 & 21 \\
MXMB & 55 & 203.9 & 79 & 63 \\
STDB & 47.1 & 28.1 & 37 & 4 \\
TRT & 1512.4 & 55 & 96 & 48 \\
TLY & 43.1 & 54.2 & 53 & 27 \\
BGT & 61.9 & 163.6 & 73 & 58 \\
UZR & 48.2 & 34.3 & 42 & 26 \\
HRMR & 54.8 & 163.2 & 75 & 32 \\
UUDB & 52.2 & 120.1 & 69 & 58 \\
BTM & 54.5 & 39.9 & 42 & \\
\hline
\end{tabular}

зависимость от частоты и длины окна (для $Q_{\text {C) }}$. Также анализ карт сейсмической добротности и коэффициента затухания для разных частотных диапазонов показывает, что на более высоких частотах, на фоне крупных областей повышенного и пониженного затухания, начинают проявляться локальные, относительно небольшие районы с более высокими или низкими значениями затухания (см. рис. 6).

Возможным объяснением частотной зависимости затухания сейсмической коды может быть влияние положения рассеивателей (неоднородностей), а также разная природа сейсмических волн - на частоте 1 Гц кода представлена отраженными поверхностными волнами, на частотах $>10$ Гц - отраженными объемными волнами [Aki, Chouet, 1975]. В то же время хорошо известно существование прямой связи между частотной зависимостью $Q$ и тектонической активностью региона: активные регионы мира характеризуются низкими значениями добротности, стабильные - высокими [Aki, 1981; Sato, Fehler, 1998; Mak et al., 2004]. Если предположить, что локальное изменение затухания на разных частотах связано с распределением мелких структурных неоднородностей (разломы, трещины, разрывы и пр.), то можно попытаться оценить их размеры через длину волны $\lambda=V / f$. Принимая среднюю скорость для $S$-волн в коре Южнобайкальской впадины и ее окружения равной 3.51 км/с [Tubanov et al., 2013], получаем вариации размеров неоднородностей для центральной частоты 0.75 Гц в пределах 3.5-7.0 км, а для частоты 12 Гц - 0.20.6 км. Размеры 200-600 м соответствуют мелким блокам, составляющим зоны крупных разломов, в то время как 3-7 км - это делимость верхней части земной коры по площади всего Байкальского рифта [Ufimtsev, Skovitina, 2001].

Вариации $Q_{\mathrm{C}}$ с изменением длины окна обработки коды $W$ могут объясняться несколькими факторами: (1) неоднородным распределением «рассеивателей» в объеме среды, (2) вкладом в формирование коды многократно рассеянных сейсмических волн и (3) непостоянным значением внутреннего затухания [Wennerberg, 1993]. В настоящей работе максимальное значение $W$ выбиралось равным 40 с. При этом известно, что на таких временах рассеянное волновое поле слишком слабо и не дает вторичного рассеяния на неоднородностях [Aki, Chouet, 1975; Rautian, Khalturin, 1978; Kopnichev, 1977]. Таким образом, наиболее вероятными объяснениями изменения добротности с длиной окна можно считать вариации внутреннего затухания и вертикальную неоднородность среды.

Дополнительную информацию о природе затухания сейсмических волн можно получить при анализе двух составляющих затухания - внутреннего затухания $\left(Q_{i}\right)$ и затухания вследствие рассеяния сейсмических волн на неоднородностях среды $\left(Q_{\mathrm{sc}}\right)$. Расчет величин $Q_{i}$ и $Q_{\mathrm{sc}}$ для рассматриваемого региона показал, что в большинстве случаев больший вклад в общее затухание дает внутреннее затухание (табл. 4). Значения $Q_{i}$ и $Q_{\mathrm{sc}}$ по простиранию структур варьируются достаточно сильно, и ярко выраженные зависимости от положения сейсмической станции не наблюдаются. В то же время можно выделить несколько классов соотношений между вкладом различных компонент в общее затухание и разломной тектоникой. К первому классу относятся сейсмически активные крупные разломы, в пределах которых отмечается преобладание 
затухания на неоднородностях среды (табл. 4). Это разломы Черского, Дельтовый и Ольхонский (Морской). Ко второму классу можно отнести слабоактивные разломы, в зоне которых наблюдается либо равный вклад компонент $Q_{i}$ и $Q_{\mathrm{sc}}$ в общее затухание, либо преобладание внутреннего затухания.

Районы с промышленными карьерными взрывами (Забайкалье) также следует выделить в отдельный класс, так как тут отмечен доминирующий вклад внутреннего затухания - до 99 \%. Необходимо уточнить, что в этом случае разделение компонент затухания не несет информации о среде прохождения сейсмических волн, а напрямую связано со спецификой затухания сейсмических волн от взрывов, о чем было сказано выше.

\section{7.ЗАКЛЮЧЕНИЕ}

В результате получены детальные оценки затухания прямых объемных $S$-волн и коды в земной коре и верхней мантии Южнобайкальской впадины, входящей в состав Байкальской рифтовой системы. По записям локальных и региональных землетрясений с использованием теории однократного рассеяния [Aki, Chouet, 1975], гибридной модели [Zeng, 1991] и подхода [Wennerberg, 1993] рассчитаны значения сейсмической добротности $\left(Q_{\mathrm{S}}\right.$ и $\left.Q_{\mathrm{C}}\right)$, частотного параметра $(n)$, коэффициента затухания $(\delta)$, общего затухания $\left(Q_{\mathrm{T}}\right)$, а также проведена оценка вклада двух компонент затухания - внутреннего затухания $\left(Q_{i}\right)$ и затухания вследствие рассеяния на неоднородностях среды $\left(Q_{\mathrm{SC}}\right)$ - в общее затухание.

Значения сейсмической добротности показывают высокую зависимость от частоты в диапазоне 0.5-18.0 Гц и длины окна обработки коды (для $Q_{\mathrm{c}}$ ):

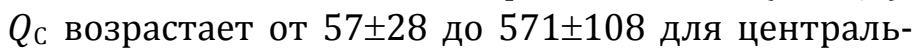
ных частот 0.75 и 12.00 Гц при длине окна обработки коды $W=10$ с и от $141 \pm 46$ до $1579 \pm 294$ на тех же частотах при $W=40 \mathrm{c}$; $Q_{\mathrm{S}}$ возрастает от 13 до 42 $\left(f_{\mathrm{C}}=0.75\right.$ Гц) и от 280 до $958\left(f_{\mathrm{C}}=12\right.$ Гц). Анализ карт сейсмической добротности и коэффициента затухания для разных частотных диапазонов показывает проявление дробной структуры поля затухания на более высоких частотах. Сравнение длины волн на разных частотах и размеров структурных неоднородностей в Байкальском рифте свидетель- ствует о том, что мелкие блоки, входящие в состав крупных разломов, могут оказывать влияние на затухание сейсмических волн на высоких частотах (6-12 Гц), в то время как на низких частотах основное влияние будет оказывать общая делимость верхней части земной коры (3-7 км).

Пространственное положение областей повышенного и пониженного затухания в Южнобайкальской впадине определяется различиями в свойствах земной коры и верхней мантии: локализация области пониженного затухания сейсмических волн согласуется с областью повышенной плотности верхней коры [Mats et al., 2001], в то время как область высокого затухания расположена в южной части впадины, где по данным сейсмотомографии выявлен выступ аномальной мантии [Gao et al., 2003]. Сравнительный анализ поля затухания сейсмических волн и геолого-геофизических характеристик среды показывает наличие прямой связи между затуханием и активными процессами в земной коре и мантии региона.

Оценка вклада внутреннего затухания $\left(Q_{i}\right)$ и затухания вследствие рассеяния сейсмических волн на неоднородностях среды $\left(Q_{\mathrm{sc}}\right)$ в общее затухание для рассматриваемого региона в целом выявила доминирующую роль внутреннего затухания. В то же время для областей крупных активных разломов наблюдается увеличение вклада рассеянной компоненты затухания $Q_{\mathrm{Sc}}$.

\section{8. БЛАГОДАРНОСТИ}

В работе использованы волновые формы, а также каталоги и бюллетени землетрясений, полученные Байкальским и Бурятским филиалами Федерального исследовательского центра «Единая геофизическая служба РАН». Авторы выражают благодарность анонимным рецензентам за ценные конструктивные замечания, способствовавшие улучшению статьи. Исследование выполнено при частичной поддержке РФФИ и Правительства Иркутской области (проект № 17-35-50011-мол_нр), РФФИ и Правительства Иркутской области (проект № 17-45-388049), а также Программы ИНЦ СО РАН «Фундаментальные исследования и прорывные технологии как основа опережающего развития Байкальского региона и его межрегиональных связей» (0341-2015-0001).

\section{9. ЛИТЕРАTУPA / REFERENCES}

Aki K., 1969. Analysis of the seismic coda of local earthquakes as scattered waves. Journal of Geophysical Research 74 (2), 615-631. https://doi.org/10.1029/JB074i002p00615.

Aki K., 1980. Attenuation of shear-waves in the lithosphere for frequencies from 0.05 to $25 \mathrm{~Hz}$. Physics of the Earth and Planetary Interiors 21 (1), 50-60. https://doi.org/10.1016/0031-9201(80)90019-9. 
Aki K., 1981. Source and scatering effects on the spectra of small local earthquakes. Bulletin of the Seismological Society of America 71 (6), 1687-1700.

Aki K., Chouet B., 1975. Origin of the coda waves: source, attenuation and scattering effects. Journal of Geophysical Research 80 (23), 3322-3342. https://doi.org/10.1029/JB080i023p03322.

Arefiev S.S., 2003. Epicentral Seismological Studies. Akademkniga, Moscow, 375 p. (in Russian) [Арефьев C.C. Эпицентральные сейсмологические исследования. М.: Академкнига, 2003. 375 с.].

Arefiev S.S., Bykova V.V., Gileva N.A., Masalsky O.K., Matveev I.V., Matveeva N.V., Melnikova V.I., Chechelnitsky V.V., 2008. Preliminary results of epicentral observations of the Kultuk earthquake, August 27, 2008. Voprosy Inzhenernoi Seismologii 35 (4), 5-15 (in Russian) [Арефьев С.С., Быкова В.В., Гилева Н.А., Масальский О.К., Матвеев И.В., Матвеева Н.В., Мельникова В.И., Чечельницкий В.В. Предварительные результаты эпицентральных наблюдений Култукского землетрясения 27 августа 2008 г. // Вопросы инженерной сейсмологии. 2008. Т. 35 . № 4. C. 5-15].

Bukina K.I., Willemson L.H., Kovachev S.A., Soloviev S.L., 1983. Amplitude curves of bulk waves of Baikal earthquakes as observed by autonomous bottom seismographs. Izvestia AN SSSR, seriya Fizika Zemli (3), 82-87 (in Russian) [Букина К.И., Виллемсон Л.Х., Ковачев С.А., Соловьев С.Л. Амплитудные кривые объемных волн байкальских землетрясений по наблюдениям автономных донных сейсмографов // Известия АН СССР, серия Физика Земли. 1983. № 3. С. 82-87].

Dergachev A.A., 1982. Technique and results of determining seismic wave absorption in the central part of the Baikal rift zone. Geologiya i Geofizika (Soviet Geology and Geophysics) 23 (6), 94-101 (in Russian) [Дергачев А.A. Методика и результаты определения поглощения сейсмических волн в центральной части Байкальской рифтовой зоны // Геология и геофизика. 1982. Т. 23. № 6. С. 94-101].

Dobrynina A.A., 2011. Coda-wave attenuation in the Baikal rift system lithosphere. Physics of Earth and Planetary Interiors 188 (1-2), 121-126. https://doi.org/10.1016/j.pepi.2011.05.008.

Dobrynina A.A., Chechel'nitskii V.V., San'kov V.A., 2011. Seismic quality factor of the lithosphere of the southwestern flank of the Baikal rift system. Russian Geology and Geophysics 52 (5), 555-564. https://doi.org/10.1016/j.rgg. 2011.04.008.

Dobrynina A.A., German V.I., 2016. Identification of weak earthquakes and industrial explosions in the area of the East Beiya open-pit mine (Khakassia, Russia). Bulletin of NNC RK (2), 96-99 (in Russian) [Добрынина А.А., Герман В.И. Распознавание слабых землетрясений и промышленных взрывов в районе Восточно-Бейского разреза (Хакасия, Россия) // Вестник НЯЦ РК. 2016. Вып. 2. С. 96-99].

Dobrynina A.A., Sankov V.A., Chechelnitsky V.V., Déverchère J., 2016b. Spatial changes of seismic attenuation and multiscale geological heterogeneity in the Baikal Rift and surroundings from analysis of coda waves. Tectonophysics 675, 50-68. https://doi.org/10.1016/j.tecto.2016.03.010.

Dobrynina A.A., Sankov V.A., Déverchère J., Chechelnitsky V.V., 2017. Factors influencing seismic wave attenuation in the lithosphere in continental rift zones. Geodynamics \& Tectonophysics 8 (1), 107-133 (in Russian) [Добрынина А.А., Саньков В.А., Девершер Ж., Чечельницкий В.В. Факторы, влияющие на затухание сейсмических волн в литосфере в зонах континентального рифтогенеза // Геодинамика и тектонофизика. 2017. Т. 8. № 1. C. 107-133]. https://doi.org/10.5800/GT-2017-8-1-0234.

Dobrynina A.A., Sankov V.A., Predein P.A., Chechelnitsky V.V., Tubanov Ts.A., 2016a. Heterogeneity of seismic wave attenuation on the Southern Pribaikalie and Transbaikalia. The Bulletin of Irkutsk State University, Earth Sciences Series 17, 46-63 (in Russian) [Добрынина А.А., Саньков В.А., Предеин П.А., Чечельницкий В.В., Тубанов Ц.А. Неоднородности поля затухания сейсмических волн на территории Южного Прибайкалья и Забайкалья // Известия Иркутского государственного университета. Серия Науки о Земле. 2016. Т. 17. С. 46-63].

Duchkov A.D. (Ed.), 1985. Heat Flow Data Catalogue of Siberia. Institute of Geology and Geophysics, Siberian Branch of the USSR Acad. Sci., Novosibirsk, 82 p. (in Russian) [Каталог данных по тепловому потоку Сибири / Ред. А.Д. Дучков. Новосибирск: ИГиГ СО АН СССР, 1985. 82 с.].

Egorkin A.V., Kun V.V., Chernyshev N.M., 1981. Absorption of longitudinal and transverse waves in the crust and upper mantle of the West Siberian plate and the Siberian platform. Izvestia AN SSSR, seriya Fizika Zemli (2), 37-50 (in Russian] [Егоркин A.В., Кун В.В., Чернышев Н.M. Поглощение продольных и поперечных волн в коре и верхней мантии Западно-Сибирской плиты и Сибирской платформы // Известия АН СССР, серия Физика Земли. 1981. № 2. С. 37-50].

Emanov A.F., Seleznev V.S., Solov'ev V.M., Chichin I.S., Kaptsov O.V., Kashun V.N., Zhemchugova I.V., Duchkov A.D., 1999. Investigation of dynamic peculiarities of seasonal variations of wave fields on vibroseismic monitoring of a medium. Geologiya i Geofizika (Russian Geology and Geophysics) 40 (4), 474-486.

Gao S., Davis P.M., Liu H., Slack P.D., Zorin Y.A., Logatchev N.A., Kogan M., Burkholder P.D., Meyer R.P., 1994. Asymmetric upwarp of the asthenosphere beneath the Baikal rift zone, Siberia. Journal of Geophysical Research: Solid Earth 99 (B8), 15319-15330. https://doi.org/10.1029/94JB00808.

Gao S.S., Liu K.H., Davis P.M., Slack P.D., Zorin Y.A., Mordvinova V.V., Kozhevnikov V.M., 2003. Evidence for small-scale mantle convection in the upper mantle beneath the Baikal rift zone. Journal of Geophysical Research 108 (B4), 2194. https://doi.org/10.1029/2002JB002039. 
Golenetsky S.I., 1976. Structure of the epicentral field of earthquakes in Pribaikalie and Transbaikalia. Izvestia AN SSSR, seriya Fizika Zemli (1), 85-94 (in Russian) [Голенецкий C.И. Структура эпицентрального поля землетрясений Прибайкалья и Забайкалья // Известия АН СССР, серия Физика Земли. 1976. № 1. С. 85-94].

Golubev V.A., 2007. Conductive and Convective Heat Flows in the Baikal Rift Zone. Geo, Novosibirsk, 222 p. (in Russian) [Голубев B.A. Кондуктивный и конвективный вынос тепла в Байкальской рифтовой зоне. Новосибирск: Гео, 2007. 222 с.].

Gusev A.A., 1995. Vertical profile of turbidity and Coda Q. Geophysical Journal International 123 (3), 665-672. https:// doi.org/10.1111/j.1365-246X.1995.tb06882.x.

Hammond W.C., Humphreys E.D., 2000. Upper mantle seismic wave attenuation: Effects of realistic partial melt distribution. Journal of Geophysical Research: Solid Earth 105 (B5), 10987-10999. https://doi.org/10.1029/2000JB 900042.

Havskov J., Ottemoller L., 2003. SEISAN: The Earthquake Analysis Softwares for Windows, Solaris and Linux, Version 8.0. Institute of Solid Earth Physics, University of Bergen, Norway, 348 p.

Hutchinson D.R., Golmshtok A.Yu., Zonenshain L.P., Mur T.K., Scholz K.A., Klitgord K.D., 1993. Features of the sedimentary sequence of Lake Baikal based on the results of multichannel seismic surveys. Geologiya i Geofizika (Russian Geology and Geophysics) 34 (10-11), 25-36 (in Russian) [Хатчинсон Д.Р., Гольмшток А.Ю., Зоненшайн Л.П., Мур Т.К., Шольц К.А., Клитгорд К.Д. Особенности строения осадочной толщи оз. Байкал по результатам многоканальной сейсмической съемки // Геология и геофизика. 1993. Т. 34. № 10-11. С. 25-36].

Kopnichev Y.F., 1977. The role of multiple scattering in the formation of a seismogram's tail. Izvestiya Akademii Nauk SSSR, Series Fizika Zemli 13, 394-398.

Kopnichev Y.F., 1991. New data on the structure of the upper mantle of the Baikal Rift System. Doklady AN SSSR 325 (5), 944-949 (in Russian) [Копничев Ю.Ф. Новые данные о строении верхней мантии Байкальской рифтовой системы // Доклады АН СССР. 1991. Т. 325. № 5. С. 944-949].

Logachev N.A., 2001. Historic core of the Baikal rift zone. Doklady Earth Sciences 376 (1), 43-46.

Lysak S.V., 2002. Terrestrial heat flow in zones of active faults in Southern East Siberia. Geologiya i Geofizika (Russian Geology and Geophysics) 43 (8), 791-803.

Mak S., Chan L.S., Chandler A.M., Koo R., 2004. Coda Q estimates in the Hong Kong region. Journal of Asian Earth Sciences 24 (1), 127-136. https://doi.org/10.1016/j.jseaes.2003.10.001.

Mats V.D., Ufimtsev G.F., Mandel'baum M.M., Alakshin A.M., Pospeev A.V., Shimaraev M.N., Khlystov O.M., 2001. The Baikal Basin in the Cenozoic: Structure and Geologic History. Siberian Branch of RAS Publishing House, Filial "Geo", Novosibirsk, 252 p. (in Russian] [Мац В.Д., Уфимцев Г.Ф., Мандельбаум М.М., Алакшин А.М., Поспеев А.В., Шимаpaев M.Н., Хлыстов О.М. Кайнозой Байкальской рифтовой впадины: строение и геологическая история. Новосибирск: Изд-во СО РАН, филиал «Гео», 2001. 252 с.].

Mitchell B.J., 1981. Regional variation and frequency dependence of $\mathrm{Q} \beta$ in the crust of the United States. Bulletin of the Seismological Society of America 71 (5), 1531-1538.

Mitchell B.J., Cong L., Ekström G., 2008. A continent-wide map of 1-Hz Lg coda Q variation across Eurasia and its relation to lithospheric evolution. Journal of Geophysical Research: Solid Earth 113 (B4), B04303. https://doi.org/ $10.1029 / 2007 J B 005065$.

Pavlenko O.V., 2012. About the updated general seismic zoning maps of the territory of the Russian Federation OSR-97* and maps OSR-2012. Earthquake engineering. Safety of Structures (5), 16-22 (in Russian) [Павленко О.В. Об актуализированных картах общего сейсмического районирования территории Российской Федерации 0СР-97* и картах ОСР-2012 // Сейсмостойкое строительство. Безопасность сооружений. 2012. № 5. C. 16-22].

Potapov V.A., Chechelnitsky V.V., Ivanov F.I., 1996. Characteristics of scattering of seismic waves from nearby earthquakes in Pribaikalie. In: N.A. Logachev, K.G. Levi (Eds.), Geophysical studies in East Siberia at the turn to the 21st century. Nauka, Novosibirsk, p. 172-176 (in Russian] [Потапов В.А., Чечельницкий В.В., Иванов Ф.И. Характеристика рассеяния сейсмических волн близких землетрясений в Прибайкалье // Геофизические исследования в Восточной Сибири на рубеже XXI века / Ред. Н.А. Логачев, К.Г. Леви. Новосибирск: Наука, 1996. C. 172-176].

Predein P.A., Dobrynina A.A., Tubanov T.A., German E.I., 2017. CodaNorm: A software package for the body-wave attenuation calculation by the coda-normalization method. SoftwareX 6, 30-35. https://doi.org/10.1016/j.softx.2016. 12.004 .

Pulli J.J., 1984. Attenuation of coda waves in New England. Bulletin of the Seismological Society of America 74 (4), 1149-1166.

Puzyrev N.N. (Ed.), 1981. Interior of Baikal from Seismic Data. Nauka, Novosibirsk, 105 p. (in Russian) [Недра Байкала по сейсмическим данным / Ред. Н.Н. Пузырев. Новосибирск: Наука, 1981. 105 c.].

Puzyrev N.N. (Ed.), 1993. Detailed Seismic Studies of the Lithosphere Using P and S waves. Nauka, Novosibirsk, 199 p. (in Russian) [Детальные сейсмические исследования литосферы на Р и S-волнах / Ред. Н.Н. Пузырев. Новосибирск: Наука, 1993. 199 с.].

Radziminovich N.A., 2010. Focal depths of earthquakes in the Baikal region: a review. Izvestiya, Physics of the Solid Earth 46 (3), 216-229. https://doi.org/10.1134/S1069351310030043. 
Radziminovich N.A., Tubanov C.A., Miroshnichenko A.I., 2018. Epicentral zones in the South and Central Baikal areas. In: Geodynamics and minerageny of the North and Central Asia. Materials of the 5th All-Russia Scientific and Practical Conference. Publishing House of the Buryatian State University, Ulan-Ude, p. 303-305 (in Russian) [Радзиминович Н.А., Тубанов Ц.А., Мирошниченко А.И. Эпицентральные зоны Южного и Центрального Байкала // Геодинамика и минерагения Северной и Центральной Азии: Материалы V Всероссийской научнопрактической конференции. Улан-Удэ: Изд-во Бурятского госуниверситета, 2018. С. 303-305].

Rautian T.G., Khalturin V.I., 1978. The use of the coda for determination of the earthquake source spectrum. Bulletin of the Seismological Society of America 68 (4), 923-948.

Sankov V.A., Lukhnev A.V., Miroshnitchenko A.I., Dobrynina A.A., Ashurkov S.V., Byzov L.M., Dembelov M.G., Calais E., Déverchère J., 2014. Contemporary horizontal movements and seismicity of the south Baikal Basin (Baikal rift system). Izvestiya, Physics of the Solid Earth 50 (6), 785-794. https://doi.org/10.1134/S106935131406007X.

Sato H., Fehler M.C., 1998. Seismic Wave Propagation and Scattering in the Heterogeneous Earth. Springer-Verlag, New York, $308 \mathrm{p}$.

Shebalin N.V., Arefiev S.S., Vasiliev V.Yu., Tatevosyan R.E., 1991. From seismicity of areas to the structure of seismicity. Izvestia AN SSSR, seriya Fizika Zemli (9), 20-28 (in Russian) [Шебалин Н.В., Арефьев С.С., Васильев В.Ю., Татевосян Р.Э. От сейсмичности площадей к структуре сейсмичности // Известия АН СССР, серия Физика Земли. 1991. № 9. С. 20-28].

Sherman S.I., 1992. Faults and tectonic stresses of the Baikal rift zone. Tectonophysics 208 (1-3), 297-307. https://doi.org/10.1016/0040-1951(92)90351-6.

Sherman S.I., Dem'yanovich V.M., Lysak S.V., 2004. Seismic process and active lithospheric failure in the Baikal rift system. Geologiya i Geofizika (Russian Geology and Geophysics) 45 (12), 1458-1470.

Solonenko A., Solonenko N., Melnikova V., Shteiman E., 1997. The seismicity and earthquake focal mechanisms of the Baikal rift zone. Bulletin des Centres de Recherches Exploration-Production Elf Aquitaine 21 (1), 207-231.

Spudich P., Iida M., 1993. The seismic coda, site effects, and scattering in alluvial basins studied using aftershocks of the 1986 North Palm Springs, California, earthquake as source arrays. Bulletin of the Seismological Society of America 83 (6), 1721-1743.

Suvorov V.D., Mishenkina Z.M., Petrick G.V., Sheludko I.F., Seleznev V.S., Solovyov V.M., 2002. Structure of the crust in the Baikal rift zone and adjacent areas from Deep Seismic Sounding data. Tectonophysics 351 (1-2), 61-74. https://doi.org/10.1016/S0040-1951(02)00125-7.

Suvorov V.D., Tubanov T.A., 2008. Distribution of local earthquakes in the crust beneath central Lake Baikal. Russian Geology and Geophysics 49 (8), 611-620. https://doi.org/10.1016/j.rgg.2007.09.019.

Tubanov Ts.A., Suvorov V.D., Tsydypova L.R., 2013. Transverse-wave velocities in the crust of the Baikal rift according to the data on nearby earthquakes. In: S.V. Rasskazov, A.M. Nikishin, S.P. Primina (Eds.), Continental rifting and related processes. Materials of the Second All-Russia Symposium with International Participation and the Youth Scientific School Dedicated to the Memory of Academicians N.A. Logachev and E.E. Milanovsky. IEC SB RAS, Irkutsk, Vol. 2, p. 117-120 (in Russian) [Тубанов Ц.А., Суворов В.Д., Цыдыпова Л.Р. Скорости поперечных волн в земной коре Байкальского рифта по данным близких землетрясений // Континентальный рифтогенез, сопутствующие процессы: Материалы Второго Всероссийского симпозиума с международным участием и молодежной научной школы, посвященных памяти академиков Н.А. Логачева и Е.Е. Милановского / Ред. С.В. Рассказов, А.М. Никишин, С.П. Примина. Иркутск: ИЗК СО РАН, 2013. Т. 2. С. 117-120].

Ufimtsev G.F., Skovitina T.M., 2001. Modern structure of the eastern coast of Middle Baikal. Otechestvennaya Geologiya (2), 26-29 (in Russian) [Уфимцев Г.Ф., Сковитина T.M. Новейшая структура восточного побережья Среднего Байкала // Отечественная геология. 2001. № 2. С. 26-29].

Wennerberg L., 1993. Multiple-scattering interpretations of coda-Q measurements. Bulletin of the Seismological Society of America 83 (1), 279-290.

Zeng Y., 1991. Compact solutions for multiple scattered wave energy in time domain. Bulletin of the Seismological Society of America 81 (3), 1022-1029.

Zhadin V.V., Dergachev A.A., 1973. Estimation of seismic quality factors of the crust from records of microearthquakes (data for the West Tuva region and the Baikal rift zone). Izvestia AN SSSR, seriya Fizika Zemli (2), 17-22 (in Russian) [Жадин B.B., Дергачев А.А. Измерение добротности земной коры по записям микроземлетрясений (на примере Западной Тувы и Байкальской рифтовой зоны) // Известия АН СССР, серия Физика Земли. 1973. № 2. C. 17-22].

Zherebtsov G.A. (Ed.), 2012. Seismoionospheric and Seismoelectromagnetic Processes in the Baikal Rift Zone. Publishing House of SB RAS, Novosibirsk, 304 p. (in Russian) [Сейсмоионосферные и сейсмоэлектромагнитные процессы в Байкальской рифтовой зоне / Ред. Г.А. Жеребцов. Новосибирск: Изд-во СО РАН, 2012. 304 с.].

Zorin Yu.I., Kozhevnikov V.M., Mordvinova V.V., Turutanov E.Kh., Popov A.M., Lysak S.V., Golubev V.A., Dorofeeva R.P., 1996. Deep structure and thermal regime of the lithosphere of Central Asia. In: N.A. Logachev (Ed.), Lithosphere of Central Asia. Nauka, Novosibirsk, p. 107-114 (in Russian) [Зорин Ю.И., Кожевников В.М., Мордвинова В.В., Турутанов Е.Х., Попов А.М., Лысак С.В., Голубев В.А., Дорофеева Р.П. Глубинное строение и термический режим литосферы Центральной Азии // Литосфера Центральной Азии / Ред. Н.А. Логачев. Новосибирск: Наука, 1996. С. 107-114]. 
Анна Александровна Добрынина

канд. физ.-мат. наук, с.н.с.

Институт земной коры СО РАН

664033, Иркутск, ул. Лермонтова, 128, Россия

Геологический институт СО РАН

670047, Улан-Удэ, ул. Сахьяновой, 6а, Россия

$\triangle$ e-mail: dobrynina@crust.irk.ru

(iD) https://orcid.org/0000-0002-2087-4202

\section{Петр Алексеевич Предеин}

M.H.C.

Геологический институт СО РАН

670047, Улан-Удэ, ул. Сахьяновой, 6а, Россия

Бурятский филиал Федерального исследовательского центра «Единая геофизическая служба РАН»

670047, Улан-Удэ, ул. Сахьяновой, 6а, Россия

e-mail: crmpeter@gmail.com

\section{Владимир Анатольевич Саньков}

канд. геол.-мин. наук, зав. лабораторией

Институт земной коры СО РАН

664033, Иркутск, ул. Лермонтова, 128, Россия

Иркутский государственный университет

664003, Иркутск, ул. Ленина, 3, Россия

e-mail: sankov@crust.irk.ru

(iD) https://orcid.org/0000-0002-1066-2601

\section{Цырен Алексеевич Тубанов}

канд. геол.-мин. наук, зав. лабораторией

Геологический институт СО РАН

670047, Улан-У дэ, ул. Сахьяновой, 6а, Россия

Бурятский филиал Федерального исследовательского центра «Единая геофизическая служба РАН» 670047, Улан-Удэ, ул. Сахьяновой, 6а, Россия

e-mail: geos@gin.bscnet.ru

\section{Дарима Пурба-Доржиевна Санжиева} инженер

Геологический институт СО РАН

670047, Улан-Удэ, ул. Сахьяновой, 6а, Россия

e-mail: gindarima@mail.ru

Екатерина Алексеевна Горбунова

канд. геол.-мин. наук, м.н.с.

Институт земной коры СО РАН

664033, Иркутск, ул. Лермонтова, 128, Россия

e-mail: smallwizard@mail.ru

\section{Anna A. Dobrynina}

Candidate of Physics and Mathematics, Senior Researcher

Institute of the Earth's Crust, Siberian Branch of RAS

128 Lermontov street, Irkutsk 664033, Russia

Geological Institute, Siberian Branch of RAS

6a Sakhyanova street, Ulan-Ude 670047, Russia

\section{Petr A. Predein}

Junior Researcher

Geological Institute, Siberian Branch of RAS

6a Sakhyanova street, Ulan-Ude 670047, Russia

Buryatian Branch of Federal Research Center

'Geophysical Survey of RAS'

6a Sakhyanova street, Ulan-Ude 670047, Russia

\section{Vladimir A. Sankov}

Candidate of Geology and Mineralogy, Head of Laboratory Institute of the Earth's Crust, Siberian Branch of RAS

128 Lermontov street, Irkutsk 664033, Russia

Irkutsk State University

3 Lenin street, Irkutsk 664003, Russia

\section{Tsyren A. Tubanov}

Candidate of Geology and Mineralogy, Head of Laboratory

Geological Institute, Siberian Branch of RAS

6a Sakhyanova street, Ulan-Ude 670047, Russia

Buryatian Branch of Federal Research Center

'Geophysical Survey of RAS'

6a Sakhyanova street, Ulan-Ude 670047, Russia

\section{Darima P.-D. Sanzhieva}

Engineer

Geological Institute, Siberian Branch of RAS

6a Sakhyanova street, Ulan-Ude 670047, Russia

Ekaterina A. Gorbunova

Candidate of Geology and Mineralogy, Junior Researcher

Institute of the Earth's Crust, Siberian Branch of RAS

128 Lermontov street, Irkutsk 664033, Russia 